\section{EL PRINCIPIO DE IMPRESCRIPTIBILIDAD DE LOS DELITOS DE LESA HUMANIDAD Y SU APLICACIÓN EN EL ORDENAMIENTO JURÍDICO COLOMBIANO. UN ESTUDIO DESDE LOS DERECHOS HUMANOS Y LA INTERPRETACIÓN JURÍDICA*}

\author{
THE PRINCIPLE OF APPLICABILITY OF CRIMES \\ AGAINST HUMANITY AND ITS APPLICATION IN THE \\ COLOMBIAN LEGAL SYSTEM. A STUDY FROM THE \\ HUMAN RIGHTS AND LEGAL INTERPRETATION
}

O PRINCÍPIO DA APLICABILIDADE DE CRIMES CONTRA A HUMANIDADE E SUA APLICAÇÃO NO ORDENAMENTO JURÍDICO COLOMBIANO. UM ESTUDO DOS DIREITOS HUMANOS E DA INTERPRETAÇÃO JURÍDICA
Omar Huertas Díaz ${ }^{a}$ ohuertasd@unal.edu.co Fecha de recepción: 23 de Septiembre 2014 Fecha de revisión:25 de Septiembre 2014 Fecha de aceptación: 23 de Octubre 2014

\title{
Resumen
}

El trabajo que se presenta a continuación, busca abordar el desarrollo del principio de imprescriptibilidad de los delitos de lesa humanidad y la incidencia que éste trae para la trasformación de las investigaciones penales en Colombia, a partir del progreso del Derecho Penal Internacional. El lector encontrara una división claramente definida en el documento: al iniciar se encontrará con el desarrollo del Derecho Penal Internacional junto con la evolución del mismo a partir de las experiencias dejadas por las Guerras Mundiales del siglo XX y otros hechos de impacto mundial, la creación del concepto de delitos internacionales y de los delitos de lesa

\footnotetext{
* Este artículo de investigación es resultado de la reconstrucción del estado del arte y el avance de la investigación del Doctorado en Derecho, de la Universidad Nacional de Colombia. Está vinculado al Grupo de Investigación "Escuela de Derecho Penal NULLUM CRIMEN SINE LEGE UN" de la Universidad Nacional de Colombia, actualmente registrado con el Código COL0078909 en Colciencias. Línea de investigación: Derecho Penal Internacional.

a. Abogado, Profesor Asociado, Especialista en Derecho Penal y Candidato a Doctor en Derecho, Universidad Nacional de Colombia, Ph.D (C) en Ciencias de la Educación, Universidad Simón Bolívar. Mg. en Derecho Penal Universidad Libre, Máster en Derechos Humanos, Estado de Derecho y Democracia en Iberoamérica Universidad de Alcalá, España. Mg. en Educación Universidad Pedagógica Nacional. Socio de la Fundación Internacional de Ciencias Penales FICP. Miembro de honor de la Fundación de Victimología. Miembro Honorario Asociación Colombiana de Criminología. Correo electrónico: ohuertasd@unal.edu.co
}

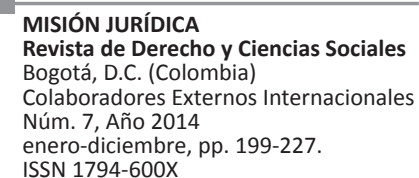


humanidad para finalizar con una aproximación de la imprescriptibilidad de este tipo de punibles internacionales. La segunda parte estará centrada en la relación de los derechos fundamentales como punto de partida en la interpretación del principio de imprescriptibilidad, los modernos Estados de Derecho y los delitos de lesa humanidad; en la tercera parte, se estudiará las consecuencias de esta relación entre la ley, los derechos y los delitos de lesa humanidad. Para finalizar se presentará una análisis sobre la incidencia que trae la aplicación del principio de imprescriptibilidad de los delitos contra la humanidad en el ordenamiento jurídico colombiano, máxime en la actual crisis de derechos que se desarrolla en nuestro país, en atención al conflicto bélico interno que se desarrolla hace más de 60 años.

\section{PALABRAS CLAVE}

Derecho Penal Internacional, principio de imprescriptibilidad, delitos de Lesa Humanidad, Derechos Humanos.

\section{ABSTRACT}

This study seeks to address the development of the principle of applicability of crimes against Human Rights and the impact it brings to the transformation of criminal investigations in Colombia, from the progress of international criminal law. The reader will find a clear-cut division in the document in the beginingyou will find the development of international criminal law with its evolution from the experiences left by the World Wars of the twentieth century and other events of global impact, creating the concept of international crimes and crimes against humanity to end with an approximation of the applicability and imprescriptibility of this type of international punishmentse; the second part will focus on the relationship of fundamental rights as a starting point in the interpretation of the principle of applicability, the modern state of law and crimes against humanity; in the third part, the consequences of this relationship between law, rights and crimes against Human Rights will be studied. An entry on the incident that brings the principle of applicability of crimes against humanity in the Colombian legal system, especially in the current human rights crisistaking place in our country, will be presented for completion in attention to internal armed conflict that has developed for more than 60 years.

\section{KEY WORDS}

International Criminal Law, Principle of Applicability, Crimes Against Humanity, Human Rights.

\section{RESUMO}

0 trabalho apresentado a seguir pretende abordar o desenvolvimento do princípio da imprescritibilidade dos crimes de lesa humanidade e o impacto que isso traz para a transformação das investigações criminais na Colômbia, a partir do progresso do Direito Penal Internacional. 0 leitor encontrará uma divisão clara no documento: ao início, encontrará o desenvolvimento do direito penal internacional com sua evolução a partir das experiências deixadas por guerras mundiais do século $\mathrm{XX}$ e outros eventos de impacto global, a criaçâo do conceito de crimes internacionais e crimes de lesa humanidade, para concluir com uma aproximação da aplicabilidade deste tipo de punição internacional internacionais. A segunda parte incidirá sobre a relação dos direitos fundamentais como um ponto de partida para a interpretação do princípio da imprescritibilidade, o moderno Estado de Direito e crimes de lesa humanidade; na terceira parte, as consequências dessa relação entre lei, direitos e crimes de lesa humanidade são consideradas. Para finalizar será apresentada uma análise sobre o impacto que traz a aplicação do princípio da imprescritibilidade dos crimes contra a humanidade no sistema jurídico colombiano, especialmente na crise atual dos direitos que se realiza no nosso país, em resposta ao conflito armado interno que ocorre há mais de 60 anos.

\section{PALAVRAS-CHAVE}

Direito Internacional Penal, princípio da imprescriptibilidade, crimes de Lesa Humanidade, os Direitos Humanos.

\section{INTRODUCCIÓN}

Colombia, desde el mismo nacimiento como Estado independiente, ha sufrido de una fuerte lucha por el poder, lo que se ha traducido en violencia por mantenerlo. Esta lucha de clases, de intereses, de culturas, de economías, sufrió una transformación desde el proceso político vivido en las décadas de los años 30 y 40 del siglo $\mathrm{XX}$, en donde el pertenecer a uno de los partidos 
políticos tradicionales era causal de agresión de los miembros del otro grupo. Dicha violencia política llevó a que sectores de oposición de los diferentes gobiernos de turno, conformaran grupos guerrilleros con clara tendencia de izquierda, quienes vieron en la toma de las armas una opción válida que justificaba la lucha por los cambios sociales que se reclamaban. Así mismo, nacieron los grupos políticos opositores, también con influencia ideológicas de izquierda, quienes vieron en el activismo político una forma válida de participación y discusión sobre los cambios que debían generarse al interior del Estado colombiano, los cuales permitieran cerrar la brecha socio-económica que se estaba generando, una distribución equitativa de los recursos y los demás cambios que permitieran una igualdad real entre las personas.

Con el transcurrir del tiempo, esas luchas armadas y políticas, no dieron el resultado propuesto por los actores que los profesaban. Al contrario, los partidos políticos tradicionales, junto con la clase dirigente y de predominación económica, crearon una sostenibilidad de los mismos a través de las instituciones estatales. Basta ver la creación del Frente Nacional, solución que dieron los partidos tradicionales colombianos para frenar la violencia que ellos mismos habían generado. Sin embargo, esta solución sólo permitió la permanencia de éstos en el poder. No cesó la violencia. La solución realmente lo que hizo fue relegar a los demás actores sociales y políticos dando como consecuencia el fortalecimiento de los grupos guerrilleros existentes, además de la creación de nuevos grupos insurgentes.

Fue para la década de los años 80 cuando las luchas violentas tomaron el rumbo que hoy en día aún mantienen. Con la entrada del tráfico de drogas ilegales a Colombia, y con ello la lucha por el control de sectores geográficos, de producción y exportación de éstas, entran nuevos grupos a jugar en esa violencia. Nacen así los denominados "carteles del narcotráfico", grupos que no sólo generaron influencia a nivel político sino que también conformaron "alas" armadas como ejércitos personales. Es decir, otro grupo armado ilegal, con intereses particulares.

De la mano y financiados por los recientes carteles del narcotráfico, se crean los grupos paramilitares cuyo único objetivo sería proponer la lucha armada en contra de la guerrillas en el territorio colombiano, bajo una postura de defensa de los intereses de las personas que se veían afectadas por el actuar de dichos grupos armados de izquierda. Así, inicia para Colombia, la violencia sistemática que hasta el día de hoy se mantiene, en donde se buscó la exterminación de todas aquellas personas que fueran opositoras de las políticas del gobernante de turno o de los intereses económicos de la clase dominante, ya fueran éstas miembros de grupos políticos o sólo por manifestar seguir las ideologías que profesaban sobre los cambios sociales que reclamaban dichas organizaciones. Al mismo tiempo, las guerrillas alzadas en armas continuaban en su actuar por fuera del Derecho, transformando su lucha y su forma de financiación al encontrar en el narcotráfico un sector económico a explotar debido a que su fabricación y distribución eran una fuente de obtención de recursos muy importante.

Aunque el panorama social, político y económico de Colombia no era el mejor, de forma alterna el Estado colombiano inicio un proceso de protección de los derechos humanos. La suscripción por parte de Colombia de diferentes tratados de derecho internacional de los derechos humanos, tales como la Convención para la Prevención del Delito de Genocidio (ONU, 1948), las cuatro Convenciones de Ginebra (ONU, 1949), la convención sobre el Estatuto de los Refugiados y los Apátridas (ONU, 1951), el Pacto Internacional de Derechos Civiles y Políticos (ONU, 1966) así como el Pacto Internacional de Derechos Económicos, Sociales y Culturales del mismo año, Convención contra la Tortura $\mathrm{y}$ otros tratos o penas crueles, inhumanos o degradantes (ONU, 1984), los Protocolos I y II (1977) adicionales a las Convenciones de Ginebra, la Convención Sobre los Derechos del Niño (ONU, 1989), el Estatuto de Roma y la creación de la Corte Penal Internacional (ONU, 1998), así como los tratados regionales sobre la misma materia como la Convención Americana Sobre Derechos Humanos (1969), el Protocolo Adicional a la Convención Americana Sobre Derechos Humanos en materia de Derechos Económicos, Sociales y Culturales (1988), la Convención Interamericana para Prevenir, Sancionar y Erradicar la Violencia Contra la Mujer "Convención de Belem Do Pará"(1995), entre otras; reflejaban la iniciativa de crear una voluntad política de protección por parte del Estado colombiano hacía los civiles y los combatientes del conflicto, era un paso para poner 
fin a la violencia vivida en el largo transcurrir de esos años de guerra interna.

Un proceso muy parecido al que se vivió en el mundo entero después de los nefastos resultados que arrojaron las dos guerras mundiales, en especial en la segunda de ellas. Es claro que con la caída de régimen Nazi en Alemania, y con la crisis humanitaria dejada por éste durante su permanencia, los países entienden que se debe crear un fuerte régimen legislativo internacional que permitiera la intervención de la comunidad internacional sobre las situaciones particulares en cada Estado, así como el cambio de paradigma del Estado, en donde, a partir de las obligaciones adquiridas a través de la ratificación de esa legislación internacional, éste debía generar garantías suficientes para la protección del ser humano, independiente de si se tratara de un ciudadano o un extranjero en su territorio.

De este modo nace la Declaración Universal de los Derechos Humanos de 1948, en donde los Estados parte reconocen al ser humano como la máxima expresión y finalidad del Derecho, como también se comprometen a la protección del mismo y a garantizarle el respeto por los derechos que la misma Carta Internacional trae. De la misma manera, comienza una era de creación del marco internacional de diferentes instrumentos internacionales de protección de los derechos humanos y la regulación de los conflictos bélicos entre Estados o en conflictos civiles internos, tal y como se señalará anteriormente al listar algunos de los convenios más importantes sobre la materia.

Si bien este Corpus Iuris de protección de los derechos del ser humano, regiría hacia el futuro, no pudiendo reparar las acciones ya acaecidas en la Segunda Guerra Mundial, el presente reclamaba también acciones sobre los hechos ya vividos durante el Holocausto. En la búsqueda de dar soluciones efectivas al nuevo reto que se enfrentaban los "Aliados"que combatieron a los nazis, nace entonces la Carta de Londres y con ella los principios y procedimientos que se llevarían dentro de los juicios en contra de los mandos nazis que participaron en la "solución final" de los judíos, opositores del régimen y combatientes. Las practicas llevadas a cabo en estos tribunales, así como el reconocimiento de los tipos de delitos por los que se juzgaron a los mandos militares nazis, es el inicio del Derecho Penal Internacional (DPI), continuado en el trasegar de los años 90 del siglo $\mathrm{XX}$, con la constitución de los tribunales penales internacionales $\mathrm{Ad} \mathrm{Hoc}$, cuyo fin era el juzgamiento sobre la responsabilidad penal de dirigentes y miembros de grupos religiosos o étnicos, que causaron diferentes violaciones a los derechos humanos y que, al igual que con los miembros del partido nazi, se debían tomar medidas de carácter penal, aunque no instituidas con antelación, para sancionar tan atroces conductas que se generaron en la ex Yugoslavia desde 1991 o en Ruanda desde el 1 enero y hasta el 31 de diciembre de 1994.

De acuerdo con lo anterior, el Estado colombiano se enfrenta en la actualidad con una difícil situación en materia de lucha contra la impunidad por las acciones que se cometieron en estos largos años de conflicto: ¿Qué se debe hacer con los casos en que se hallen conductas que puedan ser tipificadas como delitos de lesa humanidad, pero que al momento de la comisión del punible en el Estado colombiano, dicha actuación no se podía considerar como infracción penal? De un lado se tiene el respeto por las bases en que se funda el Estado de Derecho así como del Derecho Penal, como son el principio de legalidad penal y el principio de la irretroactividad; y del otro se encuentran las obligaciones internacionales derivadas de los tratados sobre Derechos Humanos, Derecho Internacional Humanitario y el Derecho Penal Internacional, de individualizar y juzgar a los autores y partícipes de acciones que configuren delitos contra la humanidad, de la misma manera de garantizar a las víctimas directas e indirectas de estos punibles, conocer la verdad sobre los hechos constitutivos del delito.

Lo anterior nace de la siguiente situación jurídica para Colombia: como ya se enunció, con el establecimiento del Tribunal Internacional de Núremberg a través del Acuerdo de Londres de 1945 y sus correspondientes principios, se crean los crímenes contra la humanidad, inicia el ciclo del Derecho Penal Internacional, una carrera que se concluyó con el Estatuto de Roma y la instauración y competencia de la Corte Penal Internacional en 1998, en donde quedaron tipificados los delitos de lesa humanidad así como los elementos que componen el tipo penal internacional. De la misma manera, en 1968, la Asamblea General de la ONU adoptó mediante resolución 2391 (XXIII), del 26 de noviembre del mismo año, la Convención Sobre la 
Imprescriptibilidad de los Crímenes de Guerra de los Crímenes de Lesa Humanidad, misma que fue establecida por el Estatuto de Roma en su artículo 29.Del otro lado, en la legislación interna se tiene que sólo hasta la ley 589 de 2000 y después con la ley 599 de 2000, se tipificaron los delitos de genocidio y desaparición forzada en la legislación penal Colombia, y se creó un bien jurídico tutelado de protección a las personas que menciona el Derecho Internacional Humanitario.

Visto el contexto social, político y jurídico del Estado colombiano, en lo atinente a la violencia sistemática que se ha ejercido por parte de los grupos armados al margen de la ley y miembros del propio Estado en contra de los mismos grupos o frente a la población civil, que han generado delitos de lesa humanidad y el correspondiente principio de imprescriptibilidad de este tipo de crímenes, la pregunta que se buscará resolver es:

¿Cómo se debe aplicar el principio de imprescriptibilidad en los delitos de lesa humanidad en Colombia, teniendo en cuenta para ello los mandatos constitucionales y la realidad jurídica y política de nuestro país; con el propósito de juzgar a personas que realizaron conductas que en su momento no constituían estos tipos penales, pero que nacieron a la vida jurídica con posterioridad a la realización de las mismas, sin que se violenten garantías fundamentales de quien es procesado penalmente y así articularlas con los principios que orientan el Derecho Penal?

De la misma manera se genera otro cuestionamiento adicional y es si la Constitución Política colombiana, con el cambio de paradigma que surge a partir de adoptar un modelo de Estado Social de Derecho, ofrece los instrumentos jurídicos que puedan dar una respuesta efectiva a la necesaria ponderación de derechos que suscita hablar de los mandatos de prohibición de imprescriptibilidad de las penas contenida en el artículo 28 Superior, del principio de legalidad penal y de la proscripción de la retroactividad de la ley penal in mala partem. Esto respecto de la obligación internacional del Estado sobre la lucha contra la impunidad en los crímenes contra la humanidad, respecto de la acción penal sobre delitos de lesa humanidad, cuando los mismos no se encontraban tipificados al momento de la comisión de dichas acciones antijurídicas.
Entonces, el presente trabajo defenderá dos hipótesis: una principal y otra subsidiaria. En la primera de ellas, la aplicación del principio de imprescriptibilidad de los crímenes de lesa humanidad en Colombia debe darse atendiendo los preceptos constitucionales y la realidad jurídica y política de nuestro país, por lo que debe establecerse un punto medio y unas restricciones, a través de la dogmática del Derecho, para no vulnerar derechos fundamentales ni desnaturalizar el Derecho Penal y Procesal Penal colombiano.

Para realizar una ponderación que permita el juzgamiento penal de personas que incurrieron en delitos contra la humanidad, cuya realización se dio con anterioridad a la entrada en vigencia del tipo penal que lo prohibía, dando así cumplimiento al principio de imprescriptibilidad de estos delitos, ya sea derivado de la Convención sobre la imprescriptibilidad de los crímenes de guerra y de los crímenes de lesa humanidad o del Estatuto de Roma, se hace necesario reconceptualizar las garantías constitucionales del procesado, en especial a lo atinente al principio de legalidad penal y la prohibición de retroactividad de la ley penal in mala partem, utilizando para ello el principio de justicia universal, los derechos de las víctimas a conocer la verdad, la justicia y la reparación, todos ellos derivados de la misma Constitución.

Así las cosas, el escrito se desarrolla en tres partes: el desarrollo del Derecho Penal Internacional, la imprescriptibilidad de los delitos de lesa humanidad, de un lado; por el otro, una teorización de los derechos humanos, para lo cual se acudirá a la construcción de ésta a partir de la vista de diferentes autores; y por último, una análisis de las posibles teorías que se pueden utilizar para interpretar jurídicamente el cuerpo normativo nacional e internacional sobre el tema en discusión. En el aparte final del documento, presentaremos las conclusiones que se derivan del análisis de los instrumentos utilizados para la elaboración del mismo. Estas tres partes desarrollan así tres líneas de investigación que se hacen parte del programa del Doctorado en Derecho de la Universidad Nacional de Colombia, de la Facultad de Derecho y Ciencias Políticas, dando cumplimiento al trabajo académico del Examen de Calificación. 


\section{EL DERECHO PENAL INTERNACIONAL Y LOS DELITOS DE LESA HUMANIDAD. UN PUNTO DE PARTIDA}

\subsection{Planteamiento inicial}

Con las cruentas guerras vividas en los primeros 50 años del siglo pasado, el mundo giros su mirada hacía los seres humanos, víctimas en último de sistemáticas y generalizadas violaciones a sus derechos durante dichos periodos de conflictos, razón por la cual el Derecho internacional reconoce una cierta subjetividad del ser humano (Carillo, 1999), quien deja de ser una parte desconocida para esta disciplina del Derecho, y entra a ser núcleo central para su protección. Dicha subjetividad es relativa, dado que no se aplica de la misma manera que al Estado, parte fundamental del Derecho internacional, pero que en desarrollo de la misma, se crea una serie de textos legales vinculantes para los Estados, y que contribuyen a la protección de hombres, mujeres, niños, niñas, etc., incluyendo normas que atribuyen hechos delictivos de manera individual y que generan así su responsabilidad (Lirola y Martín, 2001, 7-8).

Así surge el Derecho Penal Internacional, el cual se encuentra concebido como el conjunto de todas las normas de Derecho internacional que establecen consecuencias jurídico-penales para las acciones que atenten contra bienes jurídicos protegidos por normas de carácter internacional. En otras palabras, se trata de una combinación de principios de Derecho Penal y Derecho Internacional: La idea central de la responsabilidad individual y de la irreprochabilidad de una determinada conducta (macrocriminal) que proviene del Derecho penal, mientras que las clásicas figuras penales (de Núremberg), en su calidad de normas internacionales, deben clasificarse formalmente como Derecho internacional y someten de este modo la conducta en cuestión a una punibilidad autónoma de Derecho internacional (principio de la responsabilidad directa del individuo según el derecho internacional).

De la misma manera, se crea en la conciencia del Derecho Internacional que pueden existir hechos que por su impacto mundial y las aberrantes formas de ejecución de los mismos, necesitan ser tratados de manera distinta a otros punibles. De esta manera y después de una conceptualización por parte de la dogmática penal, se logró definir que los delitos de lesa humanidad son independientes de los actos propios de la guerra, no siendo entonces necesario hablar de ellos en el marco de un conflicto bélico, y que constituyen dichos delitos los tipificados en el Estatuto de Roma así: El artículo $7^{\circ}$, establece que son acciones que configuran el punible: asesinato, exterminio, esclavitud, deportación o traslado forzoso de población, encarcelación u otra privación grave de la libertad física en violación de normas fundamentales de derecho internacional, tortura, violación, esclavitud sexual, prostitución forzada, embarazo forzado, esterilización forzada o cualquier otra forma de violencia sexual de gravedad comparable, persecución de un grupo o colectividad con identidad propia fundada en motivos políticos, raciales, nacionales, étnicos, culturales, religiosos, de género definido en el párrafo 3 , u otros motivos universalmente reconocidos como inaceptables con arreglo al derecho internacional, en conexión con cualquier acto mencionado en el presente párrafo o con cualquier crimen de la competencia de la Corte, desaparición forzada de personas, el crimen de apartheid, otros actos inhumanos de carácter similar que causen intencionalmente grandes sufrimientos o atenten gravemente contra la integridad física o la salud mental o física.

Con la correspondiente definición de los delitos de lesa humanidad, el Estado colombiano, bajo el ordenamiento jurídico vigente (pasado y presente), sólo acogió la tipificación de los delitos de lesa humanidad a través de normas que entraron en vigencia en el año 2000, pero existen conductas que pueden configurar este tipo de punibles, cometidas por actores armados participantes en el conflicto armado interno, que fueron realizadas con anterioridad a las ya mencionadas normas (leyes 589 y 599 de 2000), y que dentro de las actuales condiciones sociales (en donde una gran parte de la población, sin dejar de lado las víctimas directas e indirectas dejadas por la comisión de éstas acciones), busca no dejar impune a los autores y participes que tomaron parte en la realización de las conductas.

De lo anterior se puede concluir que la investigación que se desarrollará se justifica en la medida en que se hace necesario analizar las dos posturas que se generan en el caso: las de las víctimas y la población civil en general, respecto de la no impunidad, y de otro lado el respeto 
por las garantías constitucionales del (de los) procesado(s) a no ser juzgado(s) sino por las acciones que constituían delitos previamente instituidos en un Código Penal, con vigencia de los mismos, así como que no se apliquen normas penales nuevas a casos pasados, para así poder entregar a la comunidad académica, científica y jurídica posibles soluciones al problema que se plantea, en especial a los operadores de justicia quienes, en última, son los llamados a resolver la situación.

\subsection{El Derecho Penal Internacional y crímenes de lesa humanidad}

Para iniciar la ardua labor propuesta, se hace necesario que abordemos el concepto sobre Derecho Penal Internacional. Así, Werle (2005), plantea que el Derecho Penal Internacional comprende todas las normas que fundamentan la punibilidad de individuos de forma directa en el Derecho Internacional, por tal razón, que una norma haga parte del Derecho Penal Internacional requiere que existan tres condiciones fundamentales: por un lado la norma debe describir un injusto imputable individualmente y amenazar con una pena como efecto jurídico; en segundo lugar la norma debe ser parte del ordenamiento jurídico internacional y por último la punibilidad debe existir con independencia de la recepción del tipo delictivo en el orden jurídico estatal. La primeracondición corresponde al desarrollo dogmático de la teoría del delito y la constitucionalizarían del Derecho Penal, dado que explica el principio de legalidad en materia penal, propio de los Estados modernos; el segundo constituye una garantía, dado que la norma debe cobrar vigencia de acuerdo a los principios que rigen el Derecho Internacional Público; y el tercero, permite la persecución penal de las conductas que constituyen delitos internacionales, sin que exista el impedimento de su enjuiciamiento por ausencia de tipificación dentro del Estado donde se producen, o produjeron, los hechos investigados. Con la creación de estos nuevos delitos internacionales, los crímenes de guerra, los crímenes de lesa humanidad, el genocidio y el crimen de agresión,se debe entender que éstos son crímenes de Derecho Internacional, también llamados crímenes fundamentales, crímenes de la más grave trascendencia para la comunidad internacional en su conjunto y que están sujetos a la competencia de la Corte Penal Internacional Werle (2005)
De esta manera, el objetivo de los crímenes de Derecho Internacional como nueva regulación, buscan la protección de la paz, la seguridad y el bienestar de la humanidad como los bienes jurídicos más importantes de la comunidad internacional. $\mathrm{El}$ ataque a los intereses fundamentales de la comunidad internacional le da al delito una dimensión supranacional y lo convierte en un crimen de derecho internacional. Estos crímenes afectan a la comunidad internacional en su conjunto. En consecuencia el castigo de los crímenes de derecho internacional es una tarea de la comunidad internacional $y$, por esta razón, las normas de derecho penal internacional traspasan el "blindaje de la soberanía estatal". De este modo, su relación con los intereses de la comunidad internacional proporciona al derecho penal internacional su legitimidad específica. (Werle, 2005, 81). Así, al existir este fin, la relación con los más altos intereses de la comunidad internacional queda establecida en todos los crímenes de derecho internacional a través de un elemento común o (elemento internacional): Todos los crímenes de derecho internacional requieren un contexto de ejercicio de violencia sistemático o masivo; la responsabilidad por ejemplo de esta clase de violencia recae, por lo general, en un colectivo, normalmente en un Estado.

Es claro que las nuevas tendencias de criminalidad organizada que vive el mundo entero, aunado al terrorismo mundial permite hablar de un contexto de violencia global organizada que lleva a la realización de los crímenes contra la humanidad, a través de ataques generalizados y sistemáticos contra la población civil, elementos propios del delito de lesa humanidad. Se tiene entonces que para la realización de delitos contra la humanidad deben reunirse dos situaciones, en primer lugar actos individuales frente a una población específica o en un contexto social, económico, político definido, independiente de si se está en estado de guerra o en momentos de paz, y en segundo lugar que este hecho o hechos tengan un impacto global en la comunidad. Aquí resulta especialmente útil la comparación entre el hecho global y los hechos individuales para describir la estructura del crimen. En el genocidio, el contexto de violencia organizada consiste en la destrucción (intencionalmente buscada por el autor) total o parcial o de un grupo protegido. En los crímenes de lesa humanidad está desplazada la mente del autor, porque el hecho global se ubica a través del 
impacto de las conductas desplegadas por el autor frente a la comunidad internacional.

Por otro lado, Pérez (2008) propone que el origen y desarrollo del Derecho Penal Internacional y la protección de los derechos humanos se encuentran estrechamente unidos. La raíz común se halla en el derecho internacional humanitario. Los derechos humanos (fuente de derechos individuales) y las normas del derecho penal internacional (fuente de responsabilidad individual) eran en un principio ajenos al derecho internacional tradicional centrado en el Estado. La catástrofe de la segunda guerra mundial ayudo a la progresión tanto del derecho penal internacional como de la protección de los derechos humanos. Con miras a la caracterización del individuo, el derecho penal internacional y la protección de los derechos humanos son dos caras de una misma moneda: cada persona natural es destinataria de derechos (humanos) y deberes (acciones $\mathrm{u}$ omisiones calificadas penalmente) internacionales. El derecho penal internacional es también un instrumento para la protección de los derechos humanos, reacciona ante las lesiones masivas de los derechos humanos fundamentales y ofrece una respuesta al fracaso de los mecanismos tradicionales de protección de los derechos humanos.

Entonces, el fin que busca proteger la prohibición de realización de los delitos del Derecho Penal internacional, junto con los ya mencionados intereses fundamentales de la comunidad internacional-la paz, la seguridad, y el bienestar- se encuentran protegidos, frente a ataques provenientes de distintas direcciones. De esta manera, cuando hablamos de genocidio, los intereses que protege el DPI, se perturban a través del ataque (intencional) a la existencia social de un grupo determinado. En el caso de los crímenes contra la humanidad la amenaza a la paz, la seguridad y el bienestar de la humanidad consiste en la violación sistemática o masiva de derechos humanos fundamentales de la población civil. La criminalización de este tipo de violaciones de normas y usos de la guerra busca reducir en lo posible los efectos de un conflicto armado. Generalmente los conflictos armados entre estados perturban la paz mundial. Su punibilidad depende aquí de si las conductas pueden ser consideradas como una guerra de agresión.
De lo anterior podemos afirmar que el destinatario del Derecho Penal Internacional, es la persona natural individualmente considerada, no el Estado. De esta forma, el DPI se aparta de la concepción tradicional del Derecho Internacional, conforme a la cual las consecuencias de una acción contraria a éste sólo pueden afectar al Estado Parte o a otros sujetos del DPI, estructurados de forma similar- según las reglas de la llamada responsabilidad internacional-y no al individuo que actúa. El Derecho Penal Internacional "encarna arquetípicamente la nueva calidad del derecho internacional, que no se limita ya a regular los asuntos propiamente interestatales sino que interviene profundamente en la esfera doméstica del Estado". (Werle, 2005, 90).Respecto a los crímenes de derecho internacional este autor precisa que los términos de crímenes y delitos de DI en el contexto de responsabilidad internacional del individuo son equivalentes, siendo que además, a nivel de responsabilidad internacional estatal, ya se ha abandonado tal distinción. (Pérez, 2008)

Por su parte Pérez (2008), también aborda el tema del DPI, para lo cual explica que el Derecho Internacional clásico estaba basado en una comunidad internacional en la que predominaba una estructura interestatal. En tal sentido en derecho internacional clásico poseía una finalidad principalmente de tipo relacional y competencial, es decir, la regulación de las relaciones entre estados y la distribución de las competencias entre ellos. Esta postura originó que los estados fueran considerados como los únicos sujetos del derecho internacional y desde una perspectiva doctrinal los individuos eran solo objeto del derecho internacional.

Se consideraban como sujetos de derecho internacional solo las entidades que creaban y eran destinatarias de las normas jurídicas internacionales y que poseían legitimidad para reclamar (si había cumplimiento de tales normas) o eran responsables (si las infringían). De este modo, tradicionalmente, el sistema jurídico internacional no hacía referencia al individuo sino por medio del Estado, lo cual estaba condicionado por la noción misma del Estado y por la posición de las relaciones interestatales. Un ejemplo de esto es la figura de la protección diplomática.

Una primera aproximación nos ofrece la noción de población como elemento constitutivo 
del Estado, noción que no hace referencia al individuo sino al Estado. En este marco, los individuos que no poseen la condición de residentes son calificados como extranjeros no siendo considerados parte de la población del Estado.

En igual sentido se dirigían las doctrinas dualistas, en lo referente a las relaciones entre el derecho internacional y los derechos internos estatales. La estricta separación entre el DI y los Derechos de los Estados aislaban al individuo del Derecho internacional. Únicamente si "este se convertía en derecho interno podía ser invocado por el individuo o, en sentido más amplio, por los particulares, personas físicas o jurídicas". (Pérez, 2008, 49)

Entre las teorías negadoras de la subjetividad jurídica internacional del individuo en el DI clásico, se encuentra el positivismo clásico. Esta teoría se basaba en considerar el Estado como único sujeto de derecho internacional, en tanto esta disciplina jurídica era resultado de la voluntad estatal y el individuo era solamente sujeto de Derecho interno. Pese a esta posición dominante, expresada también a través de la jurisprudencia de la Corte permanente de justicia internacional, existieron en el DI clásico algunos autores que reconocían la personalidad jurídica internacional del individuo, y por ende, la titularidad efectiva de derechos y obligaciones internacionales.

Realizando una aproximación a la evolución del Derecho Internacional se encuentra una ampliación del circulo de los sujetos del DI que ha conducido a una renovación cuantitativa del mismo. Esto se presenta debido al crecimiento del ámbito objetivo del ordenamiento jurídico internacional así como por una proliferación de los sujetos participantes, entre los que el individuo como sujeto de DI merece en la actualidad especial relevancia.

Si bien los crímenes de Derecho Internacional por lo general suponen la participación estatal, ésta no es necesaria. Por ello, la responsabilidad internacional del Estado no es una consecuencia automática de la comisión de un crimen de DI. Sobre este particular, el artículo 25.4 del estatuto de la CPI aclara que "Nada de lo dispuesto en el presente estatuto respecto de la responsabilidad penal de las personas naturales afectará la responsabilidad del estado conforme al derecho internacional". Y a la inversa, tampoco un hecho ilícito internacional conduce sin más a la punibilidad conforme al derecho internacional de las personas que intervienen en él. Sin embargo, los crímenes de derecho internacional y los actos ilícitos estatales coincidirán muchas veces. Así, por ejemplo, la eliminación de un grupo de la población puede originar tanto a la responsabilidad por genocidio de las personas que hayan intervenido en la misma como también la obligación del Estado de indemnizar a las víctimas o a sus herederos. (Werle, 2005, 91).

El hecho de que el Derecho internacional criminalice de forma directa determinadas violaciones especialmente graves de los derechos humanos, refuerza a nivel internacional la existencia de mecanismos de protección no penales. El derecho penal internacional interviene en el conflicto entre soberanía estatal y protección de los derechos humanos a favor de la humanidad. Complementa y asegura de esta forma los demás instrumentos de protección de los derechos humanos y sirve en este sentido a la protección de los derechos humanos. El derecho penal internacional es entonces doblemente subsidiario: Por un lado, frente a los mecanismos estatales y por otro, frente a mecanismos (civiles) o extrapenales. La función protectora de los derechos humanos del DPI resulta especialmente clara en los crímenes de lesa humanidad. En ellos se prevén penas para los ataques sistemáticos o masivos a derechos humanos fundamentales, como el derecho a la vida, el derecho a la integridad física, el derecho a la libertad de desplazamiento y el derecho a la dignidad humana. Con ello queda de manifiesto que la idea de humanidad es la base de la protección de los derechos humanos y del DPI. El concepto ampliado de paz que sirve de base al concepto del Derecho penal internacional conecta la protección de los derechos humanos con el derecho penal internacional (Pérez, 2008)

De la misma manera, el autor sostiene que es necesario delimitar lo que se entiende por crímenes de Derecho Internacional. Para empezar se puede señalar que se considera la existencia de dos categorías de crímenes internacionales a saber: 1. Los crímenes internacionales -stricto sensu- que vulneran normas del Ius Cogens y 2. Los crímenes establecidos por tratados y que no vulneran normas del Ius Cogens. (Pérez, 2008. 101). Ilustra su posición al citar el proyecto de estatuto de una Corte Penal Internacional (CPI) 
de la Comisión de Derecho Internacional (CDI) en 1994. Allí se consideraron dos categorías de crímenes internacionales. La primera referente a los crímenes de DI, establecidos según el DI general, constituida por el crimen de genocidio, el crimen de agresión, violaciones a las leyes de la guerra y costumbre aplicables en un conflicto armado y crímenes contra la humanidad.

Frente a su segunda clasificación, la segunda clase son los denominados treaty crimes, es decir los crímenes establecidos por el DI convencional, para lo cual la CDI estableció una selección de tratados teniendo en cuenta dos criterios: 1. Que los crímenes sean definidos por un tratado para efectos de la creación de una futura Corte Penal Internacional y que ésta pudiese aplicar la respectiva fuente convencional respetando el principio nullum crimen sine lege; y 2. Que el tratado haya creado un sistema de jurisdicción universal basado en el principio dedere aut judicare o la posibilidad para que la CPI procese el crimen, o ambas a la vez, lo cual reflejaría la preocupación internacional.

El autor trata como definición de crímenes de Derecho Internacional la de Antoni Cassese (2005, 436): "Violations of either international customary rules which are intended to protect values considered important by the whole international $c$ and consequently, bind all States out, clarify, development elaborate upon general principles of customary rules, and are applicable in the case at issue." ${ }^{\prime \prime}$ hora bien, teniendo en cuenta la definición anterior se dice que forman parte de esta categoría las violaciones graves de las normas del DI consuetudinario así como las violaciones graves del DI convencional cuando estas existan y codifiquen, desarrollen o contribuyan a la formación del DI consuetudinario, normas que deben proteger valores importantes para la totalidad de la comunidad internacional. Por ende se vinculan a los sujetos de DI a la vez que existe un interés universal en la represión de esas conductas y si el individuo actuó en su capacidad oficial no puede invocar inmunidad de jurisdicción a efectos de exoneración o atenuación

1 "Violaciones de cualquiera de las normas consuetudinarias internacionales que tienen por objeto proteger los valores considerados importantes por todo la comunidad internacional $\mathrm{y}$, en consecuencia, obligar a todos los Estados a llevar a cabo, clarificar, elaborar y desarrollar los principios generales de las normas consuetudinarias, y que son aplicables en el caso de que se trata" Traducción del autor. de responsabilidad internacional individual. (Pérez, 2008, 110).

Ahora bien, el artículo séptimo del Estatuto de Roma establece que hay dos medios que se desprenden de este, por un lado, los elementos contextuales que son indispensables para que se dé un Crimen de Lesa Humanidad (CHDL) y por el otro, las conductas que en sí constituyen estos crímenes. Del encabezado del precepto se percibe que tratamos con conductas individualizadas lo que se establece de usar el "cualquiera", a saber: "A los efectos del presente estatuto se entenderá por crimen de lesa humanidad cualquiera de los siguientes actos cuando se cometa como parte de un ataque generalizado o sistemático contra una población civil y con conocimiento de dicho ataque..." (Dondé, 2012, 97)

Así las cosas, se puede determinar que las conductas tipificadas en el precepto poseen un mismo fin, ya que los elementos contextuales señalan que objetivo debe seguir la realización de dichas conductas. Es decir, las conductas descritas deben estar dirigidas a la población civil, seguidamente es preciso establecer el significado del elemento contextual de población civil, porque de la simple lectura del precepto se desprende que este será el objeto del ataque y, posiblemente, el bien jurídico que se protege.

Dondé (2012), explica que en el artículo 8 del Estatuto de Roma, se puede identificar algunas posibles violaciones al principio de legalidad penal, de las cuales se pueden listar las siguientes:

- El uso excesivo de elementos normativos en la composición del tipo penal internacional.

- Uso de cláusulas residuales.

- La tipificación elaborada hace imposible la interpretación estricta de tipos criminales del Estatuto de Roma.

- Por otro lado, deja ver las discrepancias que surgen entre el Estatuto de Roma y los elementos que lo estructuran.

- Por último se encuentra la descripción de los elementos típicos del delito por vía de exclusión.

Debemos aclarar que para Dondé, no en todos los casos se presentan los problemas de violación del principio de legalidad en materia penal, ya que si se acude a la interpretación de los tipos penales, aplicándola al caso particular, pudiera estimarse que no existe la vulneración a este principio. 
Otra visión importante sobre los delitos contra la humanidad lo presenta Luban (2011), quien postula que frente a este tipo de delitos se hace necesario hablar de la expurgación de dichos crímenes, en vista de que cada individuo busca evitar ser víctima de este tipo de conductas por pertenecer a grupos que se encuentran fuera de las dinámicas de otros grupos de mayor jerarquía o de diferente pensamiento. Así, para este autor, los delitos de lesa humanidad tienen un contenido político respecto de las personas víctimas (Díaz, 2012). También menciona que las "leyes de la humanidad", no nacen con un interés político, sino con una "necesidad humana universal": "Ellas representan el justo reclamo del ser humano de que los desórdenes políticos nunca más incluyan la insuperable barbarie que representan los crímenes contra la humanidad". Lo anterior atendiendo las múltiples masacres, guerras $\mathrm{y}$ situaciones de exterminio de grupos que se vivió en el siglo XX.

El autor explica de forma muy precisa esta clase de delitos, sus rasgos jurídicos distintivos, que pasa con la política, explica la crítica de la demonización de Schmitt, la jurisdicción, la justicia natural y aporta algunas definiciones al delito de genocidio. Según la carta de Núremberg crímenes contra la humanidad son el asesinato, exterminio, esclavitud, deportación, y otros actos inhumanos cometidos contra toda población civil, antes o durante la guerra, o persecuciones por motivos políticos, raciales o religiosos, en ejecución de, o en conexión, con cualquier crimen de competencia del tribunal, constituyan o no violaciones del derecho doméstico del país donde fueron cometidos.

Por su parte, Pastor (2009), expone que el Estatuto de Roma de 1998 creó un sistema penal internacional, el cual está compuesto por un derecho penal material, un derecho penal procesal y un derecho de la organización judicial, el cual establece los cuerpos encargados de la realización de los procesos concretos y las relaciones y conflictos entre ellos, y entre ellos y otros sujetos como Estados, Organismos Internacionales. Tal y como se puede evidenciar en el caso de jurisdicción, se trata de una acepción laxa que se encuentra justificada tanto por razones metodológicas como por un régimen jurídico que gira en torno al poder penal de un tribunal, la CPI, y también se puede decir que el relajamiento de los conceptos jurídicos es una distinción en el derecho penal internacional. (158).

Ambos (2006), expresa que los crímenes de lesa humanidad, en cuanto a la noción han experimentado importantes desarrollos en los últimos años: su progresiva desvinculación respecto de los crímenes de guerra, la existencia de elementos que apuntan a su posible comisión por actores no estatales, el progresivo abandono de la exigencia de un móvil discriminatorio, el paulatino incremento de actos susceptibles de ser considerados como crímenes de lesa humanidad cuando ocurren los otros requisitos $\mathrm{y}$, por último, la relación de estos crímenes con las violaciones más graves de los derechos humanos, "concepto que ha adquirido el estatus de "ley dura» en los últimos tiempos, con la adopción de la Carta de las Naciones Unidas". (181).

Por su parte, Olasolo (2011), manifiesta que la CPI representa un nuevo modelo de persecución y enjuiciamiento de delitos atroces ya que: i. ha sido creada por los Estados partes por medio de un tratado internacional, ii. Constituye una organización internacional independiente con un carácter permanente, y iii. No es parte de la estrategia de las Naciones Unidas para hacer frente a situaciones de post conflicto. De manera específica la CPI se creó con el fin de conocer las situaciones de delitos atroces sucedidos a partir del primero de julio de 2002 en el territorio de cualquiera de sus 144 Estados Partes e incluso fuera de dicho territorio cuando haya una participación significativa de nacionales de los estados partes o una remisión por parte del consejo de seguridad. También la CPI opera teniendo en cuenta un régimen de complementariedad por medio del cual solo puede ejercitar su jurisdicción cuando los estados afectados no actúan, o, si lo hacen, no tienen la disposición necesaria o la capacidad suficiente para desarrollar de manera genuina sus actuaciones. (Olasolo, 2011, 39).

Sostiene este doctrinante que existe una conexión entre el concepto de responsabilidad de proteger y el mandato de la CPI ya que los dos se centran en situaciones futuras de delitos atroces y se fundamentan en cuanto a la actuación en la responsabilidad principal de los estados afectados. Por ello el Secretario general de las Naciones Unidas se refirió, en el año 2010, al estatuto de roma de la CPI como uno de los 
elementos claves en la aplicación del concepto de responsabilidad de proteger. (Olasolo, 2011, 40)

Así las cosas, es vital subrayar que la CPI comparte con las instituciones judiciales ex post facto, el compromiso de acabar con la impunidad como un medio para promover: (i). La prevención general positiva, consistente en garantizar la aplicación del derecho penal internacional y reforzar los bienes jurídicos protegidos por el mismo y (ii). La prevención general negativa, lo cual es resultado de transmitir a la clase dirigente mundial el mensaje de que aquellos que incurran en delitos atroces no quedaran impunes.

Uno de los limitantes que tiene los delitos de lesa humanidad lo propone Pérez-León(2013), al explicar que la definición de crímenes de lesa humanidad dentro de la jurisdicción del Tribunal de Núremberg, fue vincular los crímenes contra la humanidad con las otras dos categorías de crímenes: Aquellos que se comenten en estados de guerra o cuando los crímenes se comenten contra la paz.

Los crímenes de lesa humanidad son una de las categorías de crímenes de competencia de la Corte Penal Internacional y se tiene en cuenta el artículo 7 del Estatuto de Roma, en dónde se define cuáles son los actos que se consideran crímenes de lesa humanidad. Señala que para los efectos del Estatuto se entenderá por crimen de lesa humanidad cualquiera de los actos señalados en este artículo, cuando estos sean cometidos como parte de un ataque generalizado o sistemático en contra de una población, siempre y cuando el agente conozca que su acto hace parte del ataque generalizado o sistemático (Córdoba 2001).

Así mismo, se debe introducir otro elemento relacionado con los crímenes de lesa humanidad, cuya noción ha experimentado importantes desarrollos en los últimos años: $\mathrm{Su}$ progresiva desvinculación respecto de los crímenes de guerra, la existencia de elementos que apuntan a su posible comisión por actores no estatales, el progresivo abandono de la exigencia de un móvil discriminatorio, el paulatino incremento de actos susceptibles de ser considerados como crímenes de lesa humanidad cuando ocurren los otros requisitos y, por último, la relación de estos crímenes con las violaciones más graves de los derechos humanos, "concepto que ha adquirido el estatus de «ley dura» en los últimos tiempos, con la adopción de la Carta de las Naciones Unidas" (Ambos, 2006, 181).

El mismo autor plantea que el primer inconveniente que surge al analizar los crímenes de lesa humanidad es que estos no han sido codificados en ninguna legislación internacional, además de otros problemas, como son las confusiones conceptuales que han acompañado su formación; por ejemplo, su errada identificación con los crímenes de guerra o con el genocidio y por ende su tipificación en el ámbito interno se ha convertido en un desafío bastante complejo.

Así las cosas puede decirse que el concepto de crímenes de lesa humanidad surge en la forma de una noción suplementaria a la de los crímenes de guerra, pues según el Acuerdo de Londres de 1945 sólo podría hablarse de crímenes de lesa humanidad cuando ellos estuviesen en conexión con crímenes de guerra y en los casos en que la víctima fuera un nacional de Alemania o de un país neutral. El artículo sexto del Estatuto del Tribunal de Núremberg estipulaba que constituían crímenes de lesa humanidad, el asesinato, la exterminación, la esclavitud, la deportación u otros actos inhumanos cometidos contra cualquier población civil, antes o durante la guerra, o la persecución por motivos políticos, raciales o religiosos para cometer cualquier crimen que sea de la competencia del tribunal o en relación con ese crimen, implique o no el acto una violación del derecho interno del país donde se haya cometido.

Ambos y Wirth $(2006,182)$ plantean que la comisión múltiple de los delitos que se requieren para alcanzar la categoría de crímenes contra la humanidad incrementa la gravedad del delito individual, en virtud de que aumenta el peligro de la conducta del autor individual del mismo.

En sentencia del Tribunal de Casación Francés (1985), se dio por primera vez una definición de crimen contra la humanidad, donde además se da la característica de imprescriptibilidad. Más recientemente en 1997 el Tribunal Militar de Roma caso Priebke y Hass declarando la responsabilidad de asesinatos de judíos cometidos durante la Segunda Guerra Mundial, se señaló que "la imprescriptibilidad de los crímenes contra la humanidad es un principio general del ordenamiento internacional". 
Según lo anterior lo que distingue a un crimen contra la humanidad, tanto en su perversidad como en cuanto a la necesidad de medidas especiales para su des-incentivación, es sencillamente que se trata de un crimen de una brutalidad imperdonable ordenado por un Gobierno- o al menos por una organización que ejerce poder político-.(Robertson, 2007, 267)

Del desarrollo dogmático, sea anterior o posterior, se crea el Estatuto de Roma, en cuyo preámbulo se afirma que en el caso de los «crímenes más graves de trascendencia para la comunidad internacional en su conjunto», «hay que adoptar medidas en el plano nacional e intensificar la cooperación internacional para asegurar que sean efectivamente sometidos a la acción de la justicia». Al mismo tiempo recuerda «que es deber de todo Estado ejercer su jurisdicción penal contra los responsables de crímenes de derecho internacional». En lo que se refiere a la relación entre la Administración de Justicia penal internacional y nacional rige por tanto, según el Estatuto, el principio de complementariedad, que puede explicarse someramente como la subsidiariedad de la Corte Penal Internacional.

Así, el tipo penal que conlleva a la descripción del delito de lesa humanidad quedó construido. El artículo $7^{\circ}$ del ya mencionado Estatuto, establece que son acciones que configuran el punible: asesinato, exterminio, esclavitud, deportación o traslado forzoso de población, encarcelación u otra privación grave de la libertad física en violación de normas fundamentales de derecho internacional, tortura, violación, esclavitud sexual, prostitución forzada, embarazo forzado, esterilización forzada o cualquier otra forma de violencia sexual de gravedad comparable, persecución de un grupo o colectividad con identidad propia fundada en motivos políticos, raciales, nacionales, étnicos, culturales, religiosos, de género definido en el párrafo 3 , u otros motivos universalmente reconocidos como inaceptables con arreglo al derecho internacional, en conexión con cualquier acto mencionado en el presente párrafo o con cualquier crimen de la competencia de la Corte, desaparición forzada de personas, el crimen de apartheid, otros actos inhumanos de carácter similar que causen intencionalmente grandes sufrimientos o atenten gravemente contra la integridad física o la salud mental o física.
Quedan así reguladas de manera clara las conductas que constituyen delitos de lesa humanidad, incluso tipificando los diferentes significados de elementos constitutivos de las conductas descritas, tal y como se evidencia en correspondiente numeral segundo del ya citado artículo $7^{\circ}$ del Estatuto de Roma.

\subsection{Breve vista al concepto de imprescriptibilidad de los delitos de lesa humanidad}

Hasta aquí hemos visto el desarrollo conceptual que ha tenido los delitos contra la humanidad, en donde hemos expuesto las principales posturas teóricas sobe el tema $\mathrm{y}$ hemos observado los problemas que pueden generar estos tipos penales frente al principio de legalidad penal, así como los límites en la interpretación de estos crímenes. Entonces, se hace necesario que abordemos un tema anexo a estas conductas contrarias a los intereses de toda la comunidad mundial de personas, que en últimas es el eje central del presente trabajo: la imprescriptibilidad de los crímenes de lesa humanidad.

Con el objetivo de emprender el análisis de este temario, es necesario detenernos un momento para manifestar que en 1968 fue adoptada la Convención sobre la imprescriptibilidad de los crímenes de guerra y crímenes de lesa humanidad por la Asamblea General de las Naciones Unidas (Ibáñez, 2003, 300). Su finalidad era impedir que los criminales de guerra nazis quienes, bajo identidades falsas, habían encontrado refugio en terceros Estados, quedaran impunes por el simple paso de los años. De esta forma, sus disposiciones sustantivas se limitan a sentar la imprescriptibilidad de los crímenes de guerra y lesa humanidad (artículo 1), a afirmar la operatividad de tal regla independientemente del grado de participación del responsable (artículo 2), y a establecer la obligación de los Estados parte de adoptar las medidas internas necesarias para, de un lado, hacer posible la extradición de los responsables de este tipo de crímenes (artículo 3) y, de otra, impedir la prescripción del delito y/o pena (artículo 4).

Por el contrario, en la Convención ni se prevé una eventual creación de un tribunal penal internacional, ni se regulan tampoco los títulos 
de jurisdicción aplicables para el enjuiciamiento de tales crímenes por parte de los tribunales nacionales. No obstante, cuando el artículo 1 afirma que los crímenes de lesa humanidad -así como el apartheid y el genocidio- son imprescriptibles, se incluye la precisión según la cual ello es así: ... «Aún si esos no constituyen una violación del derecho interno del país donde fueron cometidos»...

Esta disposición podría interpretarse en el sentido de que la ausencia de criminalización en el lugar de comisión, no es obstáculo para la represión en terceros Estados con base en otros principios tradicionalmente admitidos en Derecho internacional, como el de beligerancia o el de personalidad activa. 0 quizá, cabría entender que la precisión se hace al objeto de impedir que la licitud de los hechos según la legislación del lugar de comisión en el momento de la perpetración, pueda ser un obstáculo para un enjuiciamiento posterior por el propio Estado (Sánchez, 2004, 199-200).

Igualmente, el análisis de este instrumento, pone de manifiesto una serie de problemas comunes relacionados con, primero, los ilícitos aplicables y, segundo, la consideración del principio de imprescriptibilidad como norma de carácter consuetudinario. La primera cuestión referente al grupo de ilícitos a los que no será aplicable la prescripción vigente en los distintos ordenamientos internos es taxativa: crímenes de guerra y crímenes de lesa humanidad. Entonces, por la pretendida retroactividad de la norma en el ámbito de los distintos ordenamientos internos, un individuo podría ser enjuiciado por la comisión de los ilícitos tipificados en la Convención, cualquiera que sea la fecha en la que se hayan cometido.

Sobre la segunda cuestión relativa a la posible naturaleza consuetudinaria del principio de imprescriptibilidad, podría concluirse que ante la gravedad inherente de estas acciones, su carácter imprescriptible es de su naturaleza. No obstante, este planteamiento supone el desconocimiento de las actitudes de los distintos Estados manifestadas en los trabajos preparatorios de la Convención de Naciones Unidas, por lo que, una posición intermedia sería el alargamiento de los plazos de prescripción en el ámbito de los ordenamientos jurídicos internos, junto a un estudio pormenorizado de la responsabilidad individual puesta en juego (Rueda, 2001, 168-169).

En cuanto a la imprescriptibilidad La Rosa (2008), explica que los delitos contra la humanidad se perfeccionaron por medio de la figura del genocidio, el cual surgió luego de la segunda guerra mundial y se precisó en los tribunales de Núremberg como el hecho de exterminar a una raza o a un grupo humano. Por su parte la Imprescriptibilidad tiene origen en el derecho anglosajón clásico donde la regla de derecho estaba expresada por nullum tempus occurit regis (el tiempo no corre para el Rey), esto quiere decir entonces que la acción podía iniciarse en cualquier momento después de la comisión del delito que no prescribía.

Para Ramelli (2011), los crímenes contra la humanidad han sido consagrados en el estatuto y en el juicio de Núremberg, así como en la ley 10 del Consejo de Administración para Alemania. En términos del artículo sexto c) del Estatuto del tribunal de Núremberg, constituyen crímenes contra la humanidad:

(...) el asesinato, el exterminio, la reducción a la esclavitud, la deportación, y todo otro acto inhumano cometido contra poblaciones civiles, antes o durante la guerra, o bien las persecuciones por motivos políticos, raciales o religiosos, cuando tales actos o persecuciones, que constituyan o no violaciones al derecho interno del país donde han sido perpetradas (o han sido cometidas luego de todo crimen de competencia del tribunal, o en relación con ese crimen).

El artículo II de la ley 10 del Consejo de Administración define los crímenes contra la humanidad de la siguiente manera:

c) Crímenes contra la humanidad: atrocidades y delitos cometidos los cuales comprenden, sin que la lista sea exhaustiva, el asesinato, el exterminio, la servidumbre, la deportación, el encarcelamiento, la tortura, la violación o cualquier otro acto cometido contra la población civil, y las persecuciones por motivos de orden político, racial o religioso, así dichos crímenes hayan constituido o no violaciones de la ley nacional del país donde fueron perpetradas. (Arteaga, 2011, 247) 
En los crímenes de lesa humanidad la extradición se aplica muy fuertemente, como consecuencia de la explícita e intensa voluntad de la comunidad internacional en reprimir las violaciones de esos crímenes. Por lo tanto, se puede concluir que la imprescriptibilidad de los crímenes de lesa humanidad forma parte del principio de jurisdicción universal. Además, se ha evidenciado que el carácter internacional de estos crímenes faculta a cualquier Estado para perseguir, a través de su propia jurisdicción penal, a los responsables, incluso aunque no exista vínculo directo entre el hecho delictivo y el ordenamiento interno. Ello, sobre la base de la naturaleza del principio de jurisdicción universal, para lo cual se ha creado un régimen jurídico ad hoc idóneo que excluya la aplicación, no sólo de la prescripción, sino de cualquier institución que pudiera obstaculizar su efectiva represión y castigo (García y López, 2000, 50,53).

Así, por ejemplo, la Corte Suprema de Justicia Argentina, Caso Priebke de 2 de Noviembre de 1995, concedio en su fallo la extradición al condenado a Italia por el requerimiento de dicho país, contrariando la naturaleza política de los delitos y la prescripción de los mismos, motivos que eran parte fundamental de la parte acusadora para no permitir dicha Extradición.En este caso fue reconocido el principio de imprescriptibilidad en el ejercicio de la acción penal con base en el delito internacional cometido y sentenciado, no sobre la base consuetudinaria del derecho internacional sino sobre la naturaleza coactiva de la norma internacional incriminadora.

\section{LOS DERECHOS HUMANOS COMO BASE PARA LA PONDERACIÓN DEL CASO}

Los planteamientos considerados hasta este momento llevan a presentar dos reflexiones iniciales: De un lado los Estados nacionales, bajo la voluntad política de protección de derechos, construyeron un marco jurídico internacional para lograr su objetivo, al que hoy en día le llamamos Derecho Internacional; del otro, las experiencias del pasado, de cruentas guerras y de crisis humanitaria dejadas por éstas, incluyeron como categoría de protección y de responsabilidad al ser humano, en la primera guerra mundial los bienes protegidos por el Derecho penal internacional y en la segunda al ser humano como responsable de comisión de delitos de Derecho internacional. Aunque a simple vista estos razonamientos estatales no deberían presentar problemas, en su aplicación al Derecho interno de cada país las cosas se tornan un poco más complejas, ya sea por la incompatibilidad que se dan entre las normas de Derecho internacional con las constituciones o con el ordenamiento jurídico propio, o por la ausencia de mecanismos de protección que efectivicen el goce de los derechos reconocidos por el Estado, a través de los tratados de Derecho internacional.

En este capítulo estudiaremos la relación que tiene los delitos de lesa humanidad y su correspondiente imprescriptibilidad de la acción penal, la impunidad y los derechos humanos. Para iniciar debemos anunciar que existe una relación inescindible entre cada uno de estos temas, ya que al hablar de derechos humanos, nos estamos refiriendo a todos los derechos que tienen los seres humanos por la simple razón de serlo. De ahí que la situación se torne más compleja.

\subsection{Los derechos humanos y su relación con la protección del ser humano}

El fin de los derechos humanos está vinculado inicialmente con intereses específicos de clase y eran el arma ideológica y política de la burguesía ascendente en contra del poder político despótico y una organización social estática. Sin embargo su presunción ontológica entendida a partir de los principios de igualdad y libertad humanas, así como su corolario político, entendido como la exigencia de que el poder político debe subordinarse a las exigencias del derecho y la razón, se han integrado como una parte pacifica de la ideología de la mayoría de los regímenes políticos contemporáneos y así, su parcialidad ha sido trascendida. (Douzinas.2008, 1)

Nino (1998) plantea, que un punto conceptual que genera confusiones, es el de la especie de derechos a la que se alude cuando se habla de derechos humanos aunque parece un leonasmo hablar de "derechos jurídicos" y huele a inconsistencia referirse a (derechos morales), tiene pleno sentido preguntarse si los derechos humanos son de índole jurídica o moral (o si corresponde a esa categoría mestiza constituida por el derecho natural o si pueden ser a la vez morales, jurídicos y "jurídico-naturales"). Aquí conviene aclarar qué quiere decir que los derechos humanos sean de una u otra índole. Se supone que las proposiciones acerca de 
derechos en general y de derechos humanos en especial (así como las que aluden a deberes, responsabilidades y demás) son equivalentes a proposiciones acerca del contenido de reglas o principios de un determinado sistema normativo. Según sea el carácter moral, jurídico o de derecho natural del sistema normativo, aludido por tales proposiciones, así será la índole de los derechos referidos por los enunciados originarios.

De un lado, como ya expusimos en acápites anteriores, son sujetos de estos derechos tanto la víctima o víctimas como el victimario, los primeros a conocer la verdad, a recibir justicia, a ser reparados y que el Estado les garantice que esas actuaciones no volverán a ocurrirles; mientras los segundos tienen derecho a un debido proceso justo y con el respeto de las garantías propias del Derecho sustancial y del Derecho procesal, a que se revisen las actuaciones de instancia por jueces superiores, a que se presuma la inocencia, se les juzgue por acciones que fueran prohibidas por la legislación penal cuando dichas leyes eran anteriores a la conducta imputada, también a que el Derecho Penal rija hacía el futuro y que sólo acoja las acciones del pasado cuando sea más benevolente para el acusado, entre otras. Así mismo, tanto unos como otros tienen derecho a que el Estado consagre en su Derecho interno recursos que efectivicen los derechos, y a que los mismos cumplan sus funciones de manera expedita y eficaz.

Sobre el debido proceso, la esencia de este derecho es, al tenor de la declaración universal de los derechos humanos, el derecho de toda persona "a ser oída públicamente y con justicia por un tribunal independiente e imparcial, para la determinación de sus derechos y obligaciones o para el examen de cualquier acusación contra ella en materia penal". Es un derecho de especial importancia porque, junto con el derecho a un recurso, tutela todos los demás derechos de la persona. En lo que concierne a las acciones judiciales emprendidas por un individuo a fin de hacer valer sus derechos, el derecho a un recurso y el derecho al debido proceso son dos caras de la misma moneda. El primero obliga al legislador a establecer recursos para este efecto, mientras que el segundo establece las características de los foros que tendrán competencia para conocer los recursos y la manera en que han de ser resueltos. El derecho al debido proceso es, sin embargo, más amplio que el derecho a un recurso. Aquel tiene una dimensión adicional pues ampara a la persona en todo asunto jurídico que le concierne, incluso en los procesos en su contra iniciados por el estado o por terceros.

Respecto del principio de legalidad Prieto Sanchis (1990), expone que históricamente, éste no se vincula tanto a la ordenación jerárquica de las fuentes del derecho como al principio de reserva o al de división competencial, entre otros motivos porque en las monarquías el Rey es fuente casi exclusiva del derecho estatal y los parlamentos no se configuran como instituciones permanentes sino como asambleas que reservan la facultad de aprobar determinadas decisiones de especial trascendencia $y$, sobre todo, el régimen tributario, por consiguiente, en su origen el principio de legalidad más que definirse como una exigencia de sometimiento de la norma inferior a la superior, según la dialéctica leyreglamento, supone una limitación a aquel poder del monarca que se manifiesta en la reserva legal de un cierto número de cuestiones importantes. El principio de legalidad surge así como una legalidad tributaria y como una legalidad penal que, merced a una teorización general por parte de los juristas alemanes de finales del siglo XIX, "van a abstraerse para concluir generalizándose en la propiedad y en la libertad"

De esta manera el principio de legalidad se manifiesta en una doble dimensión, primero la supremacía y segundo la reserva; teniendo en cuenta la primera, la ley se impone a cualquier otra norma. De acuerdo con la segunda, la ley procede frente a cualquier otra norma. La supremacía, que se ha llamado "legalidad mínima", exige únicamente que la administración respete la ley vigente, pero sin que esta goce de un ámbito material de reserva ni constituye fundamento obligado de cualquier actividad estatal. (Prieto, 1990, 168).

De otro lado Silvetroni, siguiendo a Prieto Sanchis, plantea que Nullum crimen, nulla pena, sine lege, no hay delito, no hay pena sin ley previa, el delito no es un concepto natural, material o social, el delito es un producto legal, porque nace de la ley porque antes de la ley no existe. Si se derogase todas las leyes, dejarían de existir los delitos.

La exigencia de legalidad supone que la ley penal debe ser previa, escrita, formal y estricta. 
La ley es previa cuando fue sancionada con anterioridad al hecho bajo análisis; la ley penal nunca puede regir hacia el pasado, salvo cuando es más benigna: quien durante un solo instante se vio beneficiado por los efectos de la ley penal más benigna, no puede ser luego privado de ese beneficio aunque no haya existido una actividad jurisdiccional que lo haya hecho valer; en otras palabras, la ley penal más benigna es inderogable hacia el pasado. La ley es escrita, cuando no emana de usos, practicas o cánones sociales, sino que se encuentra plasmada en un documento, mediante un uso lingüístico inamovible; no es válida la ley penal consuetudinaria salvo como eximente no escrita. La ley es formal cuando fue sancionada por el órgano con competencia legislativa (en general, las constituciones atribuyen competencia legislativa en materia penal a los parlamentos). La ley es estricta cuando se ajusta con precisión al caso bajo análisis, sin interpretaciones que extiendan su alcance a hechos diversos al abarcado por la norma. Este es un argumento a favor del principio de tipicidad estudiado previamente y da lugar a lo que se denomina estricta legalidad como antecedente de la reacción punitiva.

Del principio de legalidad se derivan diversas prohibiciones: la prohibición de retroactividad de la ley penal más gravosa; la prohibición de aplicación de pena sin ley formal, la prohibición de analogía y la prohibición de indeterminación.

El principio de legalidad es una característica distintiva de las constituciones modernas de los países civilizados. Es una de las manifestaciones más concretas del principio de libertad porque garantiza que la limitación de los derechos de los ciudadanos solo puede provenir de la ley, nunca de la voluntad del estado ni siquiera de la del órgano legislativo, porque las leyes no pueden afectar derechos hacia el pasado sino hacia el futuro. La legalidad importa al derecho de poder calcular las consecuencias jurídicas, de no ser sorprendidos por el poder, y esta es una característica esencial de la libertad.

Este principio tiene un doble carácter, por un lado es una expresión concreta del principio de culpabilidad, ya que la posibilidad de formar un juicio de reproche por la falta de motivación en la norma requiere necesariamente la previa existencia de esta; sin ley previa no hay objeto respecto del cual motivarse y, consecuentemente no puede haber culpabilidad. Esto se vincula con la posibilidad de cálculo que es una característica propia de la libertad.

Por otro lado, la legalidad es una garantía contra la arbitrariedad, en cuanto impide al estado sancionar personas mediante el simple recurso de tipificar hacia el pasado las conductas que estas cometieron, sea mediante la sanción de las leyes retroactivas, o mediante el dictado de sentencias constitutivas de la legitimidad de la conducta. (Silvestroni, 2006, 169)

La Declaración Americana en su artículo XXV reconoce el derecho al debido proceso únicamente como derecho de la persona acusada de un delito. Los artículos XV y XVII reconocen el derecho a un recurso para la tutela de los derechos constitucionales y la libertad, respectivamente, precisan apenas que los recursos deben ser rápidos. (O’Donell, 2004, 350).

Así, Martin (2004), presenta un argumento en este sentido, al proponer que los órganos estatales asumen un papel para implementar el derecho internacional de derechos humanos es fundamental, ya que muchas de las disposiciones que protegen estos derechos sólo son operativas si los integrantes de la comunidad internacional ponen en funcionamiento su sistema legal interno para darle eficacia. Así, el derecho internacional deja el cumplimiento de sus obligaciones, en última instancia, a los órganos domésticos, es decir a los Estados. Dicha característica del derecho internacional crea una relación dialéctica con el derecho interno.

Entonces, es el Estado quien debe aplicar los compromisos internacionales adquiridos a través de medidas legislativas, administrativas, judiciales o de otra índole que sean necesarias y eficaces para garantizar su cumplimiento, con ello se realiza un juicio de aplicabilidad del tratado sobre derechos humanos y su adición al Derecho interno del Estado parte. De esta manera el DI, a través de distintas técnicas, fiscaliza el accionar estatal con relación a las obligaciones internacionales. Si esta premisa es cierta con el derecho internacional en general lo es especialmente en materia de protección de los derechos humanos, donde los tratados no solo incluyen un catálogo de derechos y garantías, sino que implican para el estado obligaciones concretas acerca del modo en que se ejercen todas las atribuciones del poder. 
Por ello la gran mayoría de los tratados internacionales de derechos humanos crean deberes especiales por parte de los Estados parte en relación con la aplicación y garantía de los derechos reconocidos, en la jurisdicción doméstica. Esto es un reflejo del principio segun el cual la implementación de los derechos humanos bajo el DI es primariamente u asunto doméstico. La implementación internacional esta esencialmente limitada a la supervisión de las medidas internas adoptadas. Debido a ello, con acierto señala que los Estados no son agentes externos a los sistemas internacionales de protección de los derechos humanos, sino que son piezas centrales ya que de ellos depende la implementación de los tratados internacionales.

\subsection{Los derechos fundamentales en las constituciones de los Estados}

Alexy, explica cómo sobre los derechos fundamentales pueden formularse diferentes teorías de tipo muy diferente, por ejemplo las teorías históricas que explican el seguimiento de los derechos fundamentales, las teorías filosóficas que se ocupan de su fundamentación, y las teorías sociológicas acerca de la función de los derechos fundamentales en el sistema social. No existe ninguna disciplina en el ámbito de las ciencias sociales que no esté en condiciones de aportar algo a la problemática de los derechos fundamentales desde su punto de vista y con sus métodos. (1993,27)

Una teoría de los derechos fundamentales de la ley fundamental es una teoría de determinados derechos fundamentales positivamente válidos. Esto la distingue de las teorías de los derechos fundamentales que han tenido vigencia en el pasado (teorías históricojurídicas) como así también de las teorías sobre los derechos fundamentales en general (teorías teórico jurídicas) y de teorías sobre derechos fundamentales que no son los de la ley fundamental, por ejemplo teorías sobre los derechos fundamentales de otros Estados o teorías de los derechos fundamentales de los Estados federados.

El hacer diferencia entre las diferentes teorías no quiere decir que no existan conexiones entre ellas. Las teorías históricas jurídicas y las teorías de los derechos fundamentales de otros Estados pueden, dentro del respectivo marco de la interpretación histórica y de la interpretación comparativa, jugar un papel importante en la interpretación de los derechos fundamentales de la ley fundamental. Una conexión con las teorías teórico jurídicas resulta, por ejemplo, del hecho de que en ellas de lo que se trata es, entre otras cosas, de las estructuras posibles y necesarias de los derechos fundamentales. El hecho de que determinados derechos fundamentales tengan vigencia significa que están dadas todas las estructuras necesarias, y algunas de las posibles, de los derechos fundamentales. Por ello, una teoría sobre determinados derechos fundamentales validos puede beneficiarse por una parte de los conocimientos teórico- jurídicos y, por otra parte, contribuir a ellos a través del análisis de su materia. Justamente para comprender este tipo de conexiones es importante diferenciar lo conectado. (Alexy, 1993,27)

De otro lado, los derechos fundamentales han tenido una gran influencia sobre la concepción de las nuevas constituciones en el mundo. El constitucionalismo no sería lo que es en la actualidad si no fuera por éstos. Las normas que sancionan el estatuto de los derechos fundamentales, junto a aquellas que consagran la forma de Estado y las que establece el sistema económico, son las decisivas para definir el modelo constitucional de sociedad. Sin que se puedan considerar estas tres cuestiones como compartimientos estancos, habida cuenta de la inescindible correlación. Así, se da un estrecho nexo de interdependencia genético y funcional, entre Estado de Derecho y los derechos fundamentales, ya que el estado de derecho exige e implica para hacerlo garantizar los derechos fundamentales mientras que estos exigen e implican para su relación al Estado de Derecho. (Pérez, 1998)

Continua este autor mencionando que el tipo de Estado de Derecho (liberal o social) proclamado en los textos constitucionales dependen del alcance y significado que en ellos se asigne a los derechos fundamentales, que, a su vez, ven condicionado su contenido por el tipo de Estado de Derecho en que se formulan. De igual modo, la constitución económica representa el soporte material de la actuación de los derechos fundamentales, porque esa constitución económica se haya integrada, en gran medida, por aquellos derechos fundamentales que delimitan el régimen de propiedad, la libertad de empresa, 
el sistema tributario o el marco de las relaciones laborales y la seguridad social.

La concepción de los derechos fundamentales determina, en este modo, la propia significación del poder público, al existir una íntima relación entre el papel asignado a tales derechos y el modo de organizar y ejercer las funciones estatales. Los derechos fundamentales constituyen la principal garantía con que cuentan los ciudadanos de un Estado de Derecho de que el sistema jurídico y político en su conjunto se orienta hacia el respeto y la promoción de la persona humana, en su estricta dimensión individual (Estado liberal de derecho), o conjugando esta con la exigencia de solidaridad resultado de la componente social y de la vida humana (Estado social de derecho).

Los derechos fundamentales se presentan en la normativa constitucional como un conjunto de valores objetivos básicos (la doctrina germana los califica por ello de Grundwert) y, al propio tiempo, como el marco de protección de las situaciones jurídicas subjetivas.

Según Mir Puig, del derecho a la legalidad surgen unas tensiones institucionales que son relativas a las garantías de taxatividad y tipicidad. La garantía de taxatividad o de lex certa exige que la conducta prohibida sea definida en la ley con la mayor concreción posible; es, por tanto, un mandato dirigido al legislador, cuyo enjuiciamiento se proyecta sobre la ley misma y cuyo cauce natural de revisión constitucional es el del recurso de constitucionalidad o la cuestión de constitucionalidad.

De ahí que la garantía de tipicidad exige que la aplicación de la ley sea previsible para sus destinatarios y no desborde el límite establecido por el tenor legal, siendo por tanto un mandato dirigido a los tribunales cuyo cauce de revisión constitucional es el recurso de amparo. (Mir Puig, 2010, 19).

\subsection{Análisis de las implicaciones de la aplicación del principio de imprescriptibilidad de los delitos contra la humanidad, vista desde los derechos humanos}

El artículo 29 Constitucional prescribe que toda persona que habite o se encuentre dentro del territorio Colombiano tiene derecho a un debido proceso. De este derecho fundamental se desprenden garantías para quien está siendo procesado, entre ellas, en primer lugar, el principio de legalidad. Dicho principio, traído desde el Derecho penal de la ilustración, consiste en que nadie será juzgado sino a través de tipos penales previamente establecidos por la ley.

En segundo lugar, como garantía que tiene la persona que está siendo juzgada por un tribunal penal en Colombia, es que la nueva legislación penal que expida el legislador no podrá ser aplicada a un caso en donde no se había dado la vigencia de esa nueva normatividad. Principio que va de la mano -y podría decirse que son inescindibles- con el de la legalidad en materia penal.

Por último, la misma Constitución garantiza que la ley favorable prevalecerá sobre la desfavorable y que dicha prevalencia estará a favor de la persona que está siendo juzgada.

Múltiples han sido las interpretaciones que han tenido dichos principios en especial en el desarrollo de la sentencia C-578 de 2002, en cuyos argumentos se estudió la constitucionalidad del tratado de Roma para Colombia, así como las diferentes sentencias de Constitucionalidad que han analizado las diferentes reformas penales.

También se tiene que el artículo 28, inciso final, de la Constitución Política prohíbe que existan penas y medidas de seguridad imprescriptibles, con lo cual a priori se podría afirmar que sería inaplicable el principio de imprescriptibilidad en el Estado Colombiano, dado que el carácter de norma superior de la Constitución no permitiría dar una interpretación diferente a su postulado.

Ahora bien, también se tiene que a lo largo de la historia de la humanidad, en especial con el Derecho desarrollado en la posguerra del siglo pasado, se ha dado especial importancia al ser humano como benefactor de derechos y especial protección de la ley; en ese sentido el DI, en especial el de los Derechos Humanos y del Derecho Internacional Humanitario ha desarrollado una normatividad que busca juzgar aquellos actos de violencia extrema que sean atentatorios no solamente de bienes del ser humano individual, sino de la humanidad como sujeto de Derecho. Así las cosas las Naciones 
Unidas, a través del Estatuto De Roma, formuló un tipo penal especial para aquellas personas que cometieran crímenes que afecten a la humanidad en razón en su impacto. Colombia ratifico dicho tratado para el año 2002, entrando en vigencia para el territorio Colombiano en esa fecha, razón por la cual, y atendiendo al principio de legalidad, los colombianos serían juzgados a partir de dicha época por este tipo de delitos respetando de esta manera los ya mencionados principios de favorabilidad e irretroactividad de la ley penal.

Las enseñas que nos dejó el pasado siglo en materia de Derechos humanos, nos permiten hoy reflexionar acerca de la necesidad de aplicar el principio de imprescriptibilidad de los delitos de lesa humanidad, vista desde la perspectiva de protección de estos derechos. Esto de acuerdo a las experiencias vividas en los Tribunales Penales Internacionales que han juzgado, antes y después del Estatuto de Roma, a personas por haber cometidos crímenes contra la humanidad.

Desde el Holocausto judío vivido en la Segunda guerra Mundial y los posteriores juicios de Núremberg, este tribunal permitió delinear conceptos claros sobre estos delitos. Primero los definió como delitos autónomos, desligándolos de las acciones que se derivaban de los crímenes de guerra, en cuya consecuencia, los delitos de lesa humanidad se pueden cometer en momentos de guerra o en estados de paz. Como segundo, se comenzó la creación dogmática de la responsabilidad penal individual internacional respecto de estos delitos, junto con la correspondiente obligación de los Estados de la persecución de los victimarios a través de la declaración de imprescriptibilidad de la acción penal $\mathrm{y}$, sin no, como tercer punto, las competencias y legislación sobre los tribunales internacionales en materia penal, en caso de la ausencia de acción de los Estados.

También permitió establecer una justicia universal, diferente a la justicia interna de los Estados. Claro es que el Estado es el llamado a garantizar la protección, promoción y efectivización de los derechos humanos, de ahí que en los casos de graves violaciones a los derechos humanos, el deber estaría en las investigaciones efectivas para individualizar a los responsables, realizar un juicio con respecto de derechos y garantías así como la imposición de sanciones derivadas de las conductas delictuales.
Pero nada más lejos de este "deber ser" es lo que hoy pasa en buena parte del Mundo.

Realmente, la justicia interna no es efectiva. Largos procesos, vencimientos de términos para el juzgamiento de personas y la alta burocracia e inmersión de otros poderes en la jurisdicción penal, conllevan a una realidad diferente de la efectiva investigación y juzgamiento de delitos de lesa humanidad generadores de graves violaciones a los derechos humanos. Así, lo que esta justicia genera es un alto grado de impunidad. Un ejemplo de inmersión de los poderes respecto de los otros está en los estados de excepción que ha vivido Colombia durante el siglo XX y las suspensiones de derechos fundamentales, es un claro ejemplo de la crisis del Estado, y sus consecuencias sobre la afectación de los derechos de los seres humanos.

Hoy en día no podemos desconocer que la impunidad de los crímenes de derechos humanos se haya convertido en un fenómeno global, que conlleva a negaciones sobre los derechos de las víctimas y que permite, en algunos casos, que se recaiga en más violaciones a derechos. Casos como la dictadura Argentina regida por la Junta Militar, y las posteriores leyes de amnistía e indulto promulgadas, son otros ejemplos de impunidad, ya no generada por la inactividad de la jurisdicción penal, sino como una clara política de Estado de dar perdón a quienes causaron horrores que cobraron sacrificios sobre los derechos de quienes fueron víctimas de desaparición forzada, torturas o ejecuciones sumarias. Nada diferente a la realidad jurídico-política que se vive en Colombia, respecto de las desmovilizaciones de grupos armados al margen de la ley a través de la ley de Justicia y Paz (Ley 975 de 2005)

Pensamos que la justicia, como valor y fin de la Constitución y del ordenamiento jurídico, es un complemento de los mismos derechos humanos, de ahí que sostengamos que es necesario el enjuiciamiento de las personas que han cometido delitos contra la humanidad, pasados, presentes y, esperando que no fuera así, futuros. No discutiremos sobre las acciones que generan delitos de lesa humanidad, ya que a partir del año 2002, con el ratificación del Estatuto de Roma, además de la ley 599 de 2000, en Colombia la tipificación de éstos cobraron vigencia; la discusión central que planteamos está dirigida a que se debe aplicar la acción penal a las acciones del pasado que constituyen graves violaciones 
contra los derechos humanos, las cuales impactan de manera generalizada a la comunidad mundial en razón al actuar cruel con que se generó el delito. La justicia es realmente el remedio que mejor puede sanar las torsiones psíquicas que las miles y millones víctimas han sufrido.

Esta posición se toma bajo dos razones. La reivindicación de los vulnerados, el conocimiento de la verdad y la garantía de no repetición de estas acciones; además, que la justicia sea monopolio del Estado, evitando así la venganza como forma de justicia privada y mecanismo de violación de derechos.Debemos aclarar que nuestra primera posición no busca de ninguna manera generar un sistema judicial legítimo de venganza, es decir, a toda costa debemos "hacer pagar a los responsables", sino que es consecuente con los deberes del Estado respecto de la protección y restablecimiento de derechos, así como el mismo derecho "social" que tiene los habitantes de Colombia, como los del mundo, de conocer el por qué, el cómo, el cuándo y las cusas que generaron el accionar criminal y el correspondiente delito.

Lo difícil de la aplicación de los juzgamientos de delitos de lesa humanidad en Colombia, producidos con anterioridad al año 2000, y el principio de imprescriptibilidad, no está en tomar la decisión de procesarlos, está en la justificación que permita superar los problemas de vulneración de derechos del procesado, en especial al principio de legalidad y de irretroactividad penal, ya que,si se observa el debate desde los elementos que lo estructuran, la aplicación conllevaría al respeto de los derechos de víctimas y de la comunidad pero a la vez se sacrificaría los derechos del procesado que, no por el hecho de ser acusado de un delito contra la humanidad, deja de ser sujeto de derechos.

Estas razones nos llevan a pasar al siguiente capítulo, donde se analizará la argumentación jurídica como medio para la interpretación y correspondiente ponderación de los derechos que aquí se colisionan, buscando generar herramientas conceptuales para generar una posible solución.

\section{INTERPRETACIÓN ENTRE LEY, DERECHOS FUNDAMENTALES Y DELITOS DE LESA HUMANIDAD}

Hasta aquí el trabajo propuesto ha permitido delinear la problemática que genera hablar de delitos de lesa humanidad, imprescriptibilidad de estos delitos y la necesidad de tipificarlos, investigarlos y generar justicia de acuerdo a la magnitud de los hechos juzgados. También se desarrolló el trato que ha tenido el juzgamiento de dichos punibles en la Corte Suprema de Justicia colombiana, enfatizando en aquellos supuestos de hecho en donde nos encontramos frente a una ausencia de tipificación penal de los delitos contra la humanidad. El presente capítulo busca presentar herramientas conceptuales que permitan resolver de mejor manera dicha situación, pues no deja de ser cierto que, pese a la postura judicial del tribunal de casación penal de Colombia, la discusión sigue en pie; para ello acudiremos a la interpretación jurídica como herramienta conceptual válida para el juez, de un lado, y del otro a la argumentación jurídica que permita la verificación y justificación de la respectiva solución.

Partimos de una definición del presupuesto Derecho como creación del ser humano, teniendo como fin la regulación de las relaciones entre personas que componen determinada sociedad, de acuerdo a la voluntad política de sus representantes y con el respecto de los derechos y garantías fundamentales que su constitución les otorgue. De esta manera, a continuación entraremos al estudio de la Teoría del Derecho, vista desde diferentes teóricos, en búsqueda de las ayudas conceptuales propuestas que permitan brindar la o las posibles soluciones al subproblema planteado.

El Derecho, como un sistema que se integra entre sí, está compuesto por diferentes estructuras jurídicas. Respecto de las estructuras fundamentales son las del derecho natural, cuyo argumento se basa en comprender al hombre como un ser consciente de que su semejante está dotado de valores fundamentales, utilizando al proceso dialógico de la historia como fundamento de su afirmación, razón por la cual dichos valores se hacen para el ser humano intangibles y por lo cual hacen parte propia de la esencia del ser humano: "son las constantes axiológicas trascendentales del derecho, ya que, en el fondo, son ellas las que han hecho posible la experiencia 
jurídica." Las estructuras del derecho positivo, como segunda tipología, son reglas jurídicas positivas que surgen a través de lo que el autor denomina "trama dialéctica de hechos y valores" relacionadas entre ellas por medio de una imprevisible red de conjeturas y coyunturas. Por último se encuentran las estructuras jurídico hermenéuticas que hacen parte de los modelos dogmáticos o hermenéuticos del derecho, que tienen como objetivo y aporte a esta disciplina presentar a la comunidad científica, así como ayudar a la ciencia jurídica a determinar los significados de los modelos jurídicos positivos actuando de manera asilada o en conjunto con el ordenamiento jurídico y operando de esta forma como una manera de meta lenguaje jurídico. (Reale, 1997)

El ideal del Derecho sería que el legislador previera todas y cada una de las conductas que el ser humano puede generar en su vida, en su comunidad, en su sociedad. Pero la realización de este objetivo no se cumple. Realmente lo que el legislador intenta hacer es prever, a través de normas jurídicas, una baraja de posibilidades de conductas que puedan ocurrir, pero éstas no pueden ser tan específicas que entren en desuso muy rápidamente, ni tan generales que no permitan que futuras relaciones se acoplen a las normas ya promulgadas, máxime en nuestra era, con las nuevas formas de relacionarse entre las personas, un sistema económico globalizado, el rompimiento de las fronteras de los Estados en sus formas de relacionarse junto con el constante avance científico y tecnológico.

De ahí que se pueda afirmar que, en todo caso, las normas jurídicas tengan texturas abiertas para su interpretación por parte del órgano autorizado para esta misión. Hart (1961)en el desarrollo de su texto se propone el desarrollo de una serie de temas que se relacionan con el Derecho, los cuales son de carácter sociólogo, lingüístico, político y filosófico, cuyo inicio es la interpretación pragmática de la vida jurídica. Para ello considera el autor que existen dos tipos de normas, en la primera, el ser humano se obliga a seguir criterios éticos que hacen parte de su formación cultural adquiridos a lo largo de su educación y que se transforman con el cambio que sufren las sociedades, las cuales se encuentran en constante desarrollo; las segundas, son aquellas de las que dispone el legislador, regulan conductas y le sirven al juez para la resolución de casos sometidos a su jurisdicción.

Hart sostiene que las normas no solo formulan órdenes coercitivas, propias del diseño de un Derecho penal, sino que confieren a las personas las facilities que les permiten crear, a través de procedimientos también establecidos por el Derecho, obligaciones y deberes entre ellas. De esta manera, el Derecho dinamiza las relaciones jurídicas y sociales (1961, p. 27-29). Por lo tanto, las normas jurídicas son aplicables a todas las personas, inclusive a las mismas que las crean, contrario a lo que sucede cuando las normas traen consigo amenazas para su cumplimiento, en cuyo caso sólo estarían diseñadas para determinadas personas: las designadas por la misma ley. (1961, p. 62).

Así, en las relaciones entre personas, existen reglas sociales que imponen obligaciones a cada ser humano que la constituye, siendo necesaria su existencia dado que éstas definen los modelos o pautas sociales, creando al final el contexto del enunciado; también, al existir la regla y su contexto social, ésta deberá ser aplicada a una persona de manera particular, ya que el actuar de este individuo queda comprendido en la regla ya establecida. (Hart, 1961, p. 85-91). Estas reglas sociales pueden ser acatadas o ser tan solo un observador de las mismas, siendo que en el primer caso estaríamos frente a un punto de vista externo y en el segundo a un punto de vista interno. (p. 89)

De esta manera, propone Hart (1961) que al momento de hablar de las reglas jurídicas, éstas están compuestas por dos tipos de reglas: las primarias, entendidas estas como las obligaciones; y las secundarias, las cuales dependerán de las primeras, pero que en todo caso modifican o crean la obligación.

Sostiene que en el Derecho no se puede hablar de que una textura cerrada, sino que, por el contrario, presenta su teoría acerca de la textura abierta en donde entiende al Derecho como una serie de reglas, pautas o criterios de conducta y principios generales que sirven como instrumento de control social de manera general. Teniendo dicha visión se hace necesario que estas reglas tengan una amplia capacidad de ver en los actos cosas y circunstancias particulares, claros ejemplos de conductas generales que el derecho busca regular. 
Para comunicar estas pautas se han utilizado dos diferentes instrumentos, a saber: la legislación y el precedente. Por un lado la legislación se entiende como aquellas reglas que regulan conductas $\mathrm{y}$, por el otro, el precedente se define como las prácticas en la vida diaria, de esta manera dichas comunicaciones a través de estos dos medios permiten diversas formas de interpretación de las mismas, algunas simples y otras complejas, esto genera ciertas dudas entre las personas que se rigen a través de dichas normas, puesto que no permiten dilucidar de manera clara lo que se busca expresar. La comunicación de las reglas, ya sea por una regulación específica o a través de prácticas generalizadas, debe ser entendida de textura abierta, es decir que dicha norma no puede llegarse a considerar el absurdo de tener todas las descripciones detalladas de la conducta que busca regular, dado que la legislación busca una regulación en abstracto de las conductas, requiriendo una interpretación de la misma al caso concreto, y permitiendo así generar diversas alternativas para su solución.

Dichas alternativas deben ser vistas desde la óptica del juez, ya que este tiene el deber de entender y darle un sentido a la referida norma, ya que sobre él recae la responsabilidad de resolver el caso que se ha puesto en controversia por las partes. Así Zagrabelsky (1992), pone a este operador como actor principal en el quehacer de la justicia, dado que es él quien, además de resolverlo, debe realizar un análisis previo a dicha solución en donde deberá, en primer orden, comprender el caso, es decir entender el sentido de lo que se propone y darle un valor al mismo, utilizando para ello las categorías del sentido de valor de las que disponga el intérprete. Estas categorías permitirán al juez conocer la dirección y la vista de los posibles resultados que deberá buscar dentro del ordenamiento jurídico la regla jurídica idónea para ser aplicada al caso en concreto. No debe confundirse que el autor trabaje un sentido subjetivo del juez al hablar de "el sentido" y "el valor" pues por el contrario explica que dado que el derecho es una norma, esta misma objetiviza los criterios del juez a través del contexto cultural objetivo que ellas desarrollan.

De esta manera, la interpretación del juez se encuentra atada a la preexistencia de una norma jurídica que regule una conducta específica, no sin negar que el operador de justicia se enfrente a casos en los cuales dicha regla no se encuentre establecida, en cuyo caso será el operador de justica quien sin tener mayor objetividad dada por el Derecho, deberá darle sentido y valor desde sus propios parámetros, cediendo así la aspiración objetiva frente a las posibles visiones subjetivas, de ahí que esta situación permite concluir que el sistema genera un defecto, ya que el punto de vista del Derecho sigue siendo inminentemente, intrínseco e indiferente al punto de vista psicológico y sociológico, donde es esencial identificar los puntos de vista utilizados por el agente que permitan indagar sobre las estructuras reales del comportamiento social.

Otra solución de interpretación que ofrece la Teoría del Derecho está en Alexy (1997), quien a través de la argumentación jurídica, presenta una propuesta teórica para la interpretación jurídica a través de la pretensión de corrección, entendida como aquellos argumentos basados tanto en los enunciados jurídicos como en los argumentos normativos generales, que permiten al juez dentro de su decisión formular y sustentar la solución dada al caso en concreto; en algunos casos como en la República Federal de Alemania en los disparos del muro por parte de los centinelas, tambien en el caso del Coronel en retiro Plazas Vega en Colombia, al decidir sobre los casos de ilegalidad de las conductas de estos militares, los jueces estás sometidos a la motivación de sus sentencias, en donde podrán formular la corrección de la norma que buscan aplicar, atándola no solo a la protección que genera ésta, sino al mandato propio del cargo que viene del propio derecho positivo.

Sin embargo, si de hablar de los casos difíciles se trata, la teoría propuesta por Dworkin (1989) plantea que las teorías de la función judicial se han vuelto mucho más complejas, aunque hay unas teorías más populares que subordinan a las leyes y normas del derecho consuetudinario en algunas situaciones no tan claras, por ello estas deben ser interpretadas antes de que sean aplicadas a nuevos casos. En ciertas ocasiones se presentan casos cuyos problemas son tan nuevos que la actual legislación no permite dirimirlos ni siquiera re interpretando la legislación actual, así las cosas el operador de justicia llamado a aplicar las normas debe legislar ya sea de manera directa o encubriendo sus argumentos. Dicha legislación promulgada por el juez se encuentra motivada por el contacto que ha tenido este con las pruebas 
y argumentos con que se movería el órgano legislativo, así, se subordina a un nivel mucho más profundo dado que la resolución de casos difíciles supedita al juez a una comprensión previa y continua del quehacer legislativo, siendo de esta manera una subordinación conceptual y política.

Los argumentos políticos justificarían una decisión política que protegería a alguna "metacolectividad" en cuanto a su todo, pero no en todos los casos esta decisión política es entendida como aquel favorecimiento, ya que dicho acto puede ser confundido como una acción virtuosa o de generosidad publica basada en un direccionamiento político o en la realización de un principio. Es claro que el legislador debe actuar con argumentos políticos siendo consecuentes los programas formulados con los argumentos esgrimidos dentro de la legislación. De esta manera, en el hipotético caso en que los tribunales fueran delegados de la legislación sería necesario que conocieran esta necesidad argumentativa en lo tocante a la política.

Como ya se explicó los argumentos que justifican una norma jurídica, son de orden político o se dan a través de un principio, siendo estos los que debe acoger el juez dentro de la fundamentación de las decisiones judiciales en los casos difíciles. Dworkin propone que la base de dicha decisión debe estar bajo los argumentos del desarrollo de un principio y no bajo las argumentaciones políticas, para lo cual presenta una serie de argumentos que permiten el desarrollo de dicha idea.

La argumentación jurídica genera conceptos controvertidos cuando de resolver casos difíciles se trata, para ello es importante dilucidar ciertos aspectos, el primero se encuentra referido a la legislación, en donde lo inicial sería encontrar las razones o motivaciones que posee determinada ley, el segundo aspecto se encamina hacia la conceptualización del o los principios que están en la base o inmersos dentro de las normas jurídicas positivas; así el juez al momento de tomar una decisión, debe identificar claramente el conjunto de principios y directrices políticas que justifique el modelo de Estado y de gobierno en donde se encuentra, lo que Dworkin denomina la organización de una teoría de la constitución. Para ello puede construir de manera alterna dicha teoría haciendo uso de la filosofía política y enfocar las características institucionales, situación ésta, que le genera herramientas que pueden poner a prueba las diferentes teorías resultantes para lograr justificar la función institucional globalizada, resultando así una validación de la teoría triunfante.

De lo anterior se tiene que el actor principal que solucionará el problema será el juez y que éste debe tomar una decisión basada en los aspectos políticos que se generaron con la comisión de estos delitos de lesa humanidad, que para nosotros debe estar justificado en el impacto que generó la comisión de actos de crueldad en contra de determinado grupo de personas en un contexto sistemático, con lo cual se debe reconceptualizar el principio de legalidad penal y de irretroactividad como elementos que estructuran un debido proceso penal a favor del enjuiciado, permitiéndole conocer todos los aspectos fácticos que se generan en la acusación, reconociéndole a la vez su condición de sujeto de derecho y, si la sentencia es de carácter condenatorio, ajustando la pena a la proporcionalidad de sus actuar, respectando el derecho a integridad personal y reconociendo la vigencia de la proscripción de las penas crueles, inhumanas o degradantes.

Los primeros avances en la aplicación de estos casos y su interpretación en Colombia fueron atendidos por la Corte Suprema de Justicia, al entender que la maldad que atañe al ser humano y el deber de protección del Estado, conlleva necesariamente a reevaluar al principio de legalidad penal frente a las regulaciones internacionales del DPI. Así, en sentencia de revisión número 34180 de la CSJ, concluyo este alto tribunal que:

Es así que el artículo 38 del Estatuto de la Corte Internacional de Justicia reconoce como fuentes de derecho, con los tratados internacionales, a la costumbre internacional, los principios generales del derecho y la jurisprudencia y la doctrina; superando a la ley como su fuente exclusiva". (Sentencia de revisión número 34180 de la CSJ)

Los análisis sistemáticos de interpretación y de argumentación jurídica, devienen de aplicar diferentes normatividades de protección. Es importante establecer que a partir de la vigencia de los Tratados de Derechos Humanos se ha universalizado el compromiso legislativo en pro 
de su reivindicación y se han precisado los niveles de protección de los habitantes del mundo, en dos sistemas interrelacionados entre sí, con la obligación doméstica de ajustar sus estándares a la sistemática internacional.

El Pacto Internacional de Derechos Civiles y Políticos, el Pacto de San José y el Convenio Europeo de Derechos Humanos, extienden el principio de legalidad al derecho internacional.

Así, el Pacto Internacional de Derechos Civiles y Políticos advierte en su artículo 15 numeral 1ำ que 'Nadie podrá ser condenado por actos u omisiones que en el momento de cometerse no fueran delictivos según el derecho nacional o internacional.'

Pero va más allá en su numeral 2o en el que de manera tajante advierte: 'Nada de lo dispuesto en este artículo se opondrá al juicio ni a la condena de una persona por actos u omisiones que, en el momento de cometerse, fueran delictivos según los principios generales del derecho reconocidos por la comunidad internacional.'

Por su parte, el Pacto de San José en su artículo 9o al consagrar el principio de legalidad no lo limita al derecho patrio señalando que: 'Nadie puede ser condenado por acciones u omisiones que en el momento de cometerse no fueran delictivos según el derecho aplicable.'

También el Convenio Europeo de Derechos Humanos al reconocer el principio de legalidad, establece en su artículo 7ํㅡㅁ una fórmula similar a la adoptada por el Pacto Internacional de Derechos Civiles y Políticos, al establecer en su numeral $1^{\mathfrak{o}}$ que: 'Nadie podrá ser condenado por una acción u omisión que, en el momento en que haya sido cometida, no constituya una infracción según el derecho nacional o internacional.' En su numeral $2^{\circ}$, advierte de manera perentoria que: 'El presente artículo no impedirá el juicio y el castigo de una persona culpable de una acción o de una omisión que, en el momento de su comisión, constituía delito según los principios generales del derecho reconocidos por las naciones civilizadas.'

Esta cláusula enunciada, tanto en la Convención Europea como en el Pacto Internacional de Derechos Civiles y Políticos, claramente alude a los principios generales del DI como fuente de derecho penal internacional, aún frente a la inexistencia de tratado o ley que así lo dispongan.

Tal flexibilización a la legalidad, que implica una restricción a las garantías del justiciable en pro de la lucha contra la criminalidad que agravia a la humanidad, se explica en que con frecuencia se trata de una manifestación delincuencial auspiciada o sistemáticamente cometida por los Estados totalitarios, que por supuesto no estarían interesados en legislar tipificando sus propios actos.

La experiencia más temprana de la flexibilización o redefinición del principio de legalidad a escala internacional se vivió en los procesos de Núremberg, regidos por unos principios, el primero de los cuales advierte que: "Toda persona que cometa un acto que constituya delito de derecho internacional es responsable de él y está sujeta a sanción."

También se encuentran los 'Principios de cooperación internacional en la identificación, detención, extradición y castigo de los culpables de crímenes de guerra, o de crímenes de lesa humanidad' estableciendo los siguientes:

1. Los crímenes de guerra y los crímenes de lesa humanidad, dondequiera y cualquiera que sea la fecha en que se hayan cometido, serán objeto de una investigación, y las personas contra las que existen pruebas de culpabilidad en la comisión de tales crímenes serán buscadas, detenidas, enjuiciadas $\mathrm{y}$, en caso de ser declaradas culpables, castigadas.

2. Todo Estado tiene el derecho de juzgar a sus propios nacionales por crímenes de guerra o crímenes de lesa humanidad.

Entonces es supremamente claro sin importar el momento de comisión del delito, el mismo debe ser juzgado, pero a la vez que el Estado en que se cometió tiene derecho a investigarlo y en dado caso a imponer las condenas de rigor.

En el mismo instrumento, en su numeral $8^{\circ}$ se dispone que:

Los Estados no adoptarán disposiciones legislativas ni tomarán medidas de otra índole que puedan menoscabar las obligaciones internacionales que hayan contraído con 
respecto a la identificación, la detención, la extradición y el castigo de los culpables de crímenes de guerra o crímenes de lesa humanidad.

\section{CONCLUSIONES}

La idea inicial del presente trabajo fue entrar en el debate que actualmente se presenta en los estrados judiciales respecto del juzgamiento de delitos de lesa humanidad cometidos con anterioridad a la entrada en vigencia de la ley 589 y 599 de 2000 y del Estatuto de Roma, en especial en lo atinente a la imprescriptibilidad de dichos delitos derivada de la Convención que lleva dicho nombre y del artículo 29 del ya mencionado Estatuto. Basta ver los debates jurídicos que se han abierto en casos como el juzgamiento del Coronel en retiro Alfonso Plazas Vega y su condena en instancias por el delito de desaparición forzada por los hechos acaecidos el 6 y 7 de noviembre de 1985, en la operación militar de la retoma del Palacio de Justicia en Bogotá; también se encuentran la providencia de la Corte Suprema de Justicia, donde se permitió abrir de nuevo la investigación por la desaparición forzada de 19 comerciantes, cuyo caso fue juzgado por la Corte Interamericana de Derechos Humanos y en donde se condenó al Estado colombiano por la violación de los derechos reconocidos a estas personas por la Convención Americana Sobre Derechos Humanos, o las providencias en donde se acepta que a los miembros de los grupos paramilitares se le investigue y juzgue por delitos de lesa humanidad.

El desarrollo de los delitos de lesa humanidad fue resultado de las épocas de violencia vividas en las dos guerras mundiales de principio y mediados del siglo XX, en donde los resultados de esa sistemática violación de los derechos de seres humanos que murieron a manos de los regímenes nazis o fascistas de la Europa de los años 40, permitió el avance en la humanización del Derecho Internacional, ya no como forma de relación entre los sujetos de esta regulación, sino, en viraje que se hizo por parte de la comunidad internacional sobre las crisis de derechos que generan los Estados, así como la creación dogmática de la responsabilidad penal internacional de los actores que generaron la crisis.

Los tribunales penales internacionales, en especial el de Núremberg, trazaron el derrotero que llevaría a la conceptualización, límites y contenidos de los delitos de lesa humanidad, hasta su tipificación internacional clara en el artículo 7 del Estatuto de Roma de 1998. Así mismo, de manera alterna, se creó una conciencia global de respeto por el ser humano y en ese compromiso se crearon inundables instrumentos internacionales de protección de los derechos humanos, algunos de ellos acogidos por las modernas constituciones de los Estados. También se encuentran el compromiso global de lucha contra la impunidad de este tipo de delitos que se materializa en la creación de dos instrumentos internacionales: La Convención sobre la imprescriptibilidad de los crímenes de guerra y crímenes contra la humanidad y posteriormente el artículo 29 del Estatuto de Roma, esta última cláusula que obliga al Estado a realizar la persecución de este tipo de delitos, sin posibilidad de renunciar a la acción penal, pero que a la vez permite que, en ausencia de actividad estatal, sea la Corte Penal Internacional quien procese, juzgue y eventualmente condene a estas personas.

Por lo anterior podemos hablar del principio de imprescriptibilidad de los delitos de lesa humanidad, como vinculante para el Estado colombiano, a partir de la entrada en vigencia del Estatuto de Roma en el territorio nacional. Sin embargo, dicho principio plantea de forma inicial un problema generado desde dos visiones: la primera es la indeterminación anterior de dicho principio como parte del derecho positivo colombiano y la segunda, la lucha contra la impunidad de este tipo de delitos como compromiso del Estado colombiano frente a la comunidad internacional. De lo anterior se puede afirmar que los jueces de Colombia se encuentran frente a un caso difícil.

El conflicto armado interno sufrido en Colombia, ha generado una crisis humanitaria de todos los órdenes, de los combatientes, de los civiles, de las instituciones, de la justicia, etc. Hoy, cuando estamos en pleno proceso de paz, el debate que se presenta sobre los delitos de lesa humanidad, sobre todo en lo tocante a la posibilidad de activismo político y de representación ciudadana de miembros de grupos guerrilleros, hace más interesante el panorama, pues de un lado ellos buscan dicha representación política, pero del otro no se puede desconocer el accionar de este o de todos los grupos participantes en el combate bélico colombiano, 
en donde se han producido bajas considerables. Sin embargo, lo más importante a rescatar, es que han generado tipos penales internacionales de competencia de la Corte Penal Internacional, de un lado, y del otro, responsabilidades penales internas, antes y después de la entrada en vigencia del actual Código Penal colombiano.

Es necesario rescatar los hechos que constituyeron dichas violaciones masivas a derechos humanos, no solo como forma de individualizar y castigar a su actores, sino como memoria histórica del conflicto que permita evidenciar lo cruento de dicho proceder con el fin de prevenir otras acciones iguales o con peores consecuencias, pero también respetando las garantías de quienes serán acusados, pues no se pueden desconocer que, aun siendo investigados por la justicia penal, siguen siendo seres humanos sujetos de derecho. Por esta razón las dificultades que se generan con la aplicación del principio de imprescriptibilidad para aquellos casos en que no se encontraba en vigencia el Estatuto de Roma, el juez, único actor llamado a resolución del caso, debe realizar una ponderación de derechos que se presentan: los derivados de las víctimas y de la comunidad en general y los del encausado penalmente. Para ello deberá acudir a criterios generados por los derechos humanos y fundamentales reconocidos por el Estado, además de utilizar una clara argumentación que permita presenta una resolución coherente al caso, basado en el Derecho aplicable siempre tomando en cuenta factores de naturaleza política y de interés general, en donde sus criterios objetivos sean las normas jurídicas nacionales e internacionales, el grado de afectación o de impacto global que se genera con la conducta delictual internacional y por último juzgando sólo las conductas que se encuadren en la descripción típica actual, junto con sus correspondientes elementos del tipo.
En todo caso, el juicio deberá respetar todas las garantías propias de los procesos penales, en especial en la fijación de la pena y su correspondiente dosificación, atendiendo a criterios de proporcionalidad, y siempre manteniendo el norte del Estado Social de Derecho: la dignidad humana. La flexibilización del principio de legalidad en materia penal, tarde o temprano conllevaría a decadencia del sistema penal, no solo como garantía, sino como piedra angular de todo el sistema jurídico, pues se convertiría en un Estado de Derecho en donde sus normas pueden variar de acuerdo a los intereses que pongan en juego, conllevando a una crisis de la seguridad jurídica y un atentado a los derechos de libertad que tienen los seres humanos, ya que no podrían conocer de manera efectiva y con anterioridad si su actuar es o no acorde a Derecho. No se debe olvidar que hablar de flexibilización de la legalidad, que implica una restricción a las garantías del justiciable en pro de la lucha contra la criminalidad que agravia a la humanidad, se explica en que con frecuencia se trata de una manifestación delincuencial auspiciada o sistemáticamente cometida por los Estados totalitarios, que por supuesto no estarían interesados en legislar tipificando sus propios actos.

La Corte Suprema de Justicia colombiana, ya ha avanzado en el análisis de las normas que relacionan a los delitos contra la humanidad, la imprescriptibilidad de éstos y los derechos en colisión cuando se habla del juzgamiento de los mismos, como ya se dejó ver. Pero el sacrificio ha sido grande, ya que ha debido re-conceptualizar el principio de legalidad y acoplarlo a un significado político y jurídico: político debido a la necesidad de represión de actos graves contra la humanidad, y jurídico en vista de los derechos de las víctimas a la verdad, justicia y reparación. 


\section{BIBLIOGRAFÍA}

- Alexy, R. (1993).Teoría de los derechos fundamentales, Centro de estudios constitucionales, Madrid.

- ___ (1997).Teoría de la Argumentación Jurídica. Madrid: Centro de Estudios Constitucionales.

- Ambos, K. \& Hoyos M. Eds. (2008). Cuestiones esenciales en la jurisprudencia de la Corte Penal Internacional. Granada. Editorial COMARES.

- Corte Suprema de Justicia. Sala de Casación Penal. (2012). Proceso número 34180 del 23 de Mayo. M.P. Bustos Martínez, J.

- Dondé, J. (2012).Tipos Penales en el Ámbito Internacionales. México: Instituto Nacional de Ciencias Penales.

- Douzinas, C. (2008). Elfin de los Derechos Humanos. Bogotá: Legis, Universidad de Antioquia.2008.

- Dworkin, R. (1989).Los Derechos en Serio. Barcelona: Ariel Derecho.1989.

- Hart,H. (1961).El Concepto del Derecho. Buenos Aires: Abeledo-Perrot.1961.

- Ibáñez, J (2008).Crisis del principio de legalidad en el derecho penal internacional. Bogotá: Ibáñez.

- Kennedy, D. (1999).Libertady Restricción en la Decisión Judicial. Bogotá: Siglo del Hombre, Ediciones Uniandes.1999.

- _ (2010).Izquierda y Derecha, Ensayos de Teoría Jurídica Crítica. Buenos Aires: Siglo Veintiuno. 2010.

- La Rosa, M. (2008).La Prescripción en el Derecho Penal. Buenos Aires: Astrea.2008

- Lirola, I.,y Martín M. M. (2001). La Corte Penal Internacional. Justicia versus Impunidad. Barcelona: Editorial Ariel.

- López, D. (2006).El Derecho de los Jueces. Bogotá. Legis, Universidad de los Andes. 2006.

- Luban, D. (2011).Una Teoría de los Crímenes Contra la Humanidad. Bogotá.
- Martin, C. (2004).Derecho Internacional de los Derechos Humanos. Distribuciones Fontamara. México.

- Mir Puig, S. (2010).Constitución y principio del Derecho Penal. Algunas Bases Constitucionales. Valencia: Tirant Lo Blanch.2010.

- Nino, C. (1998).Ética y Derechos Humanos. Un Ensayo de Fundamentación. Barcelona: Ariel Derecho.1998.

- O' Donell, D. (2004).Derecho Internacional de los Derechos Humanos Normativa Jurisprudencia y Doctrina de los sistemas Universal e Interamericano. Oficina en Colombia del alto comisionado de las Naciones Unidas para los Derechos Humanos.

- Olásolo, H. (2011).Ensayos de Derecho Penaly Procesal Internacional.Valencia: Tirant lo Blanch.

- Pastor, D. (2009).Encrucijadas del Derecho Penal Internacional y del Derecho Internacional de los Derechos Humanos. Bogotá: Pontificia Universidad Javeriana.

- Pérez, A. (1998).Los Derechos Fundamentales. Tecnos. Madrid. 1998.

- Pérez, P. (2008).La Responsabilidad Internacional del Individuo por Crímenes de Guerra. Lima: ARA Editores.

- Prieto, L. (1990).Estudios sobre derechos fundamentales. Madrid, Debate.

- Olásolo, H. (2003). Corte Penal Internacional ¿Dónde Investigar? Especial referencia a la Fiscalía en el Proceso de Activación. Valencia, España. Tirant Lo Blanch.

- Ramelli, A. (2010).Las Reglas de la Disertación Jurídica: Entre la duda y el Método. Bogotá. Temis, Universidad de los Andes.2010. 
- ___._(2011).Jurisprudencia Penal Internacional aplicable en Colombia. Bogotá: Universidad de los Andes.

- Reale, M. (1997).Teoría Tridimensional del Derecho. Madrid: tecnos.1997.

- Rueda, F. (2001). Delitos de Derecho Internacional. Barcelona, España. Editorial Bosh.

- Silvestroni, M. (2007).Teoría Constitucional del Delito. Buenos Aires: Editores del Puerto.2007.
- Uprimny, R. (1998).La universalidad de los derechos humanos: Conflictos de derechos, conceptos de democracia e interpretación jurídica.En Pensamiento Jurídico. Bogotá. Universidad Nacional. No. 9, 1998

- Werle, G. (2005).Tratado de Derecho Penal Internacional. Valencia: Tirant lo Blanch.

- Zagrebelsky, G. (1992).El Derecho Dúctil. Madrid: Editorial Trotta.1992. 